NBER WORKING PAPER SERIES

\title{
THE GIFT OF THE DYING: THE TRAGEDY OF AIDS AND THE WELFARE OF FUTURE AFRICAN GENERATIONS
}

\author{
Alwyn Young \\ Working Paper 10991 \\ http://www.nber.org/papers/w10991 \\ NATIONAL BUREAU OF ECONOMIC RESEARCH \\ 1050 Massachusetts Avenue \\ Cambridge, MA 02138 \\ December 2004
}

For Lillie, who gave more than she received. I am grateful to Mark Aguiar, Matthias Doepke, participants at the NBER Summer Institute economic growth conference, the referees of the QJE and, especially, Ho Veng-Si and Larry Katz for comments which improved this paper. The views expressed herein are those of the author(s) and do not necessarily reflect the views of the National Bureau of Economic Research.

(C) 2004 by Alwyn Young. All rights reserved. Short sections of text, not to exceed two paragraphs, may be quoted without explicit permission provided that full credit, including (C) notice, is given to the source. 
The Gift of the Dying: The Tragedy of AIDS and the Welfare of Future African Generations Alwyn Young

NBER Working Paper No. 10991

December 2004

JEL No. O1

\title{
ABSTRACT
}

This paper simulates the impact of the AIDS epidemic on future living standards in South Africa. I emphasize two competing effects. On the one hand, the epidemic is likely to have a detrimental impact on the human capital accumulation of orphaned children. On the other hand, widespread community infection lowers fertility, both directly, through a reduction in the willingness to engage in unprotected sexual activity, and indirectly, by increasing the scarcity of labour and the value of a woman's time. I find that even with the most pessimistic assumptions concerning reductions in educational attainment, the fertility effect dominates. The AIDS epidemic, on net, enhances the future per capita consumption possibilities of the South African economy.

\author{
Alwyn Young \\ Graduate School of Business \\ University of Chicago \\ Chicago, IL 60637 \\ and NBER \\ alwyn.young@gsb.uchicago.edu
}




\section{Introduction}

In coming years, the AIDS epidemic will visit upon the peoples of southern Africa a plague of immeasurable horror. The growth of HIV infection amongst African adults during the 1990s far exceeded most forecasts, with infection rates amongst pregnant women in, for example, South Africa reaching 25 percent by the year 2000 (Figure 1.1). While adults with HIV typically remain asymptomatic for 8 or 9 years, they develop AIDS soon thereafter and quickly succumb to the torturous infections and cancers which overwhelm their degraded immune systems. Thus, existing infection rates, in and of themselves, presage the imminent death of at least five million young South African adults aged 15-49 in the coming decade, without consideration of the millions among future cohorts who will be infected at birth or as young adults.

In considering the economic consequences of the AIDS epidemic, one is drawn to historical examples of similar demographic catastrophes, perhaps the most well researched of which is the Black Death in Britain in the late 14th century. Reaching Britain in 1348, and recurring in a series of waves, the Black Death is estimated to have reduced Britain's population to about half of its pre-plague level by 1377 (Hatcher 1977). As in the case of AIDS today, contemporary accounts of the human suffering brought about by the plague are depressing in the extreme. Economic data, however, paint a surprisingly different picture. With a declining labour force, real wages rose rapidly during the plague years, and then remained high throughout the 15th century, as Britain's population stagnated (Steffen 1901, Phelps Brown \& Hopkins 1956). While early scholars (e.g. Saltmarsh 1941, Hatcher 1977) argued that the 15th century was a period of continued high mortality, more recent work (e.g. Poos 1991, Goldberg 1992) has emphasized the positive role played by the high post-plague wages in increasing female labour market participation and lowering fertility, generating a self-reinforcing cycle of high incomes and labour scarcity that lasted for more than a century. Regardless of the precise mechanism, it is clear that the Black Death, in a purely economic sense, was a boon to the generations which 
Figure 1.1: HIV Prevalence - South Africa (seroprevalence tests of pregnant women)

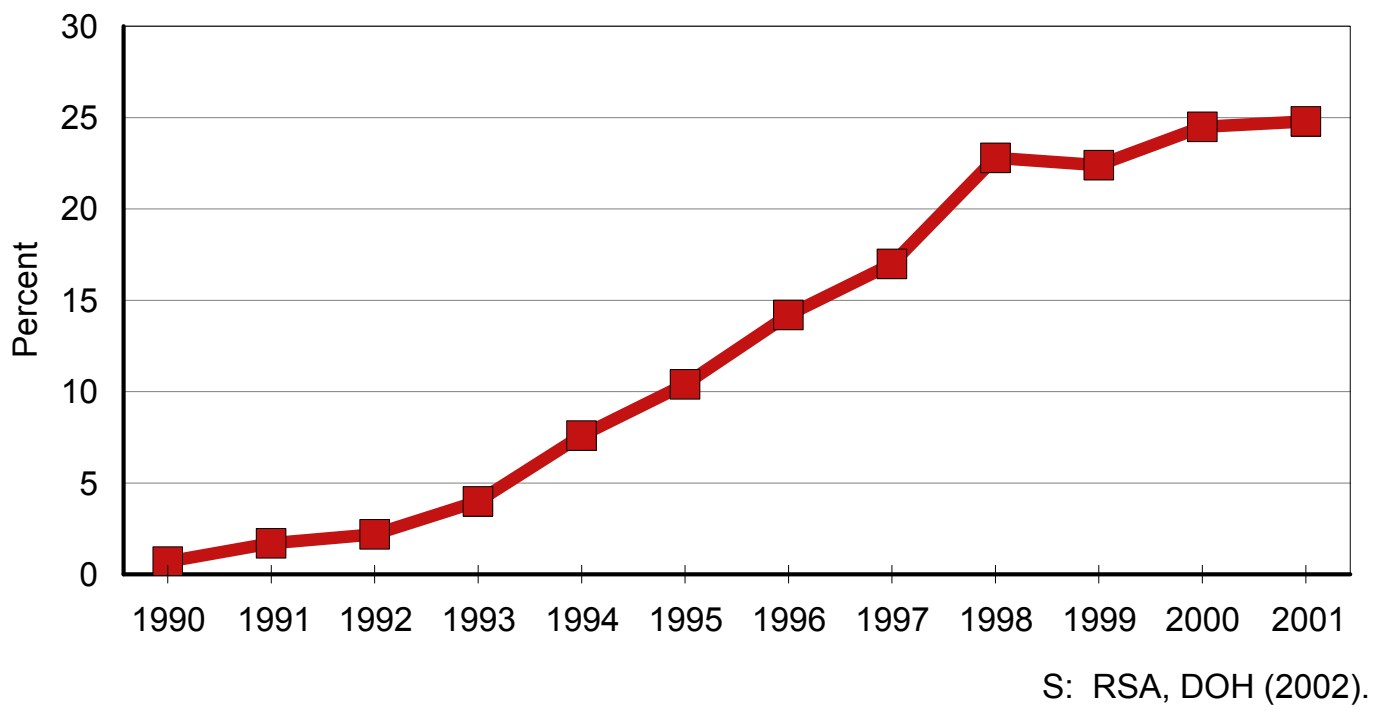


survived and succeeded it, who, for a sustained period of time, experienced living standards which were not seen again until the late 19 th century. ${ }^{1}$

In this paper I try to calculate the impact of the AIDS epidemic on future living standards in South Africa. Drawing inspiration from the recent historical work on the Black Death, I do so in the context of a Beckerian model which endogenizes participation, fertility, and education decisions with behavioral equations estimated off of household survey data. In simulating the future evolution of the South African economy, I emphasize two competing effects. On the one hand, the epidemic is likely to have a detrimental impact on the accumulation of human capital on the part of orphaned children. On the other hand, widespread community infection lowers fertility, both directly, through a reduction in the willingness to engage in unprotected sexual activity, and indirectly, by increasing the scarcity of labour and the value of women's time. I find that even with extremely pessimistic assumptions concerning reductions in educational attainment, the fertility effect dominates. The AIDS epidemic enhances the future per capita consumption possibilities of the South African economy, in effect endowing it with additional resources. These resources can be used to care for the afflicted and provide higher living standards to future generations. ${ }^{2}$

The paper proceeds as follows: Section II below details the model, a simple Beckerian household model embeded in a Solovian constant-savings macroeconomic framework. Section III explains the sources of data, while Section IV estimates the normal household behavioral coefficients and the impact of community HIV infection on fertility. Section V calibrates the macroeconomy and lays out my assumptions concerning the evolution of the epidemic and its

${ }^{1}$ See Steffen's (1901) Tafel II and Phelps Brown and Hopkins's (1965) Figure 3.

${ }^{2}$ Most studies (e.g. Over 1992, Arndt and Lewis 2000, and Bell et al 2003) estimate that AIDS will have a negative impact on future living standards, but do not consider the fertility effects emphasized in this paper. Bloom and Mahal (1995) are an exception to the general pessimism, finding, in a cross sectional regression, no relation between the incidence of AIDS and the growth of GDP per capita and, incidentally, also noting the parallels between the AIDS epidemic and the Black Death. 
impact on household behavior. Section VI then simulates the economy under a variety of scenarios, showing the importance of the fertility and education assumptions and the role Beckerian behavior plays in amplifying and extending the model's dynamics. Section VII presents empirical evidence on recent trends in the South African economy which indicate a dramatic reduction in fertility with minimal reductions in school enrollment, supporting the most optimistic of my simulations. Section VIII concludes. 


\section{Model: Becker and Solow}

I model household behavior in the Beckerian tradition, assuming that couples, endowed with human capital $\mathrm{E}_{\mathrm{m}}$ (male) and $\mathrm{E}_{\mathrm{f}}$ (female) and financial resources $\mathrm{Y}$, derive utility from the quantity of children $\mathrm{n}$, the "quality" of children q (as measured by their human capital), individual leisure $\mathrm{l}_{\mathrm{m}}$ and $\mathrm{l}_{\mathrm{f}}$, and material consumption $\mathrm{C}_{\mathrm{m}}$. In a one-period framework, each couple maximizes

$$
\text { (2.1) } U\left(n, q, l_{m}, l_{f}, C_{m}\right)
$$

subject to the non-linear budget constraint

$$
l_{m} W_{m}+l_{f} W_{f}+n t_{f} W_{f}+n q P_{q}+P_{c} C_{m} \leq Y+T^{*}\left(W_{m}+W_{f}\right)
$$

where the $\mathrm{W}_{\mathrm{i}}$ are the returns to labour market participation (functions of $\mathrm{E}_{\mathrm{i}}$ ), $\mathrm{P}_{\mathrm{c}}$ and $\mathrm{P}_{\mathrm{q}}$ the financial costs of consumption and quality, $\mathrm{T}$ the individual endowment of time, and $\mathrm{t}_{\mathrm{f}}$ the time cost of fertility, which I assume is borne principally by women. I will use household surveys to estimate a simple utility-consistent system of demand and then use it to predict behavior.

The strictures of data severely limit what can be estimated. It is difficult to measure variation across households in the cost of education, so I shall assume, perforce, that the cost of education is proportional to the cost of material consumption $\left(\mathrm{P}_{\mathrm{q}}=\mathrm{a}_{\mathrm{q}} \mathrm{P}_{\mathrm{c}}\right)$. In third world household surveys, data on assets is generally unavailable and, in any case, is endogenously determined by individual productivities. Consequently, I ignore income effects. The only remaining plausibly exogenous variation across households then lies in each couple's educational endowments, $\mathrm{E}_{\mathrm{m}}$ and $\mathrm{E}_{\mathrm{f}}$. In principal, this allows the estimation of a maximum of two price effects in each demand equation. In practice, however, spousal educational attainment is unavailable for many individuals (who are either divorced, widowed or as yet unmarried) and, even when available, moves quite closely with own education. For children, mothers are identified much more fre- 
quently than fathers. These considerations lead me to specify each component of household demand as a function of only one relative price:

(2.3) Male Labour Supply $=\operatorname{LM}\left(W_{m} / P_{c}\right)$

Female Labour Supply $=L F\left(W_{f} / P_{c}\right)$

Fertility $=F\left(W_{f} / P_{c}\right)$

Children's Education $=Q\left(W_{f} / P_{c}\right)$

As I will show further below, this simplistic system performs extraordinarily well in predicting out of sample household behavior.

The Hicksian composite commodity theorem states that the expenditure function and underlying preferences can be reexpressed as functions of the aggregates of products with common costs (Deaton and Muellbauer 1980). Despite the non-linearity of the budget constraint, this theorem can be applied to the problem above. Thus, the only requirement for consistency with utility maximization is that the matrix of compensated substitution terms for the negative of male labour supply $\left(-h_{m}=l_{m}-T\right)$, the negative of female labour supply $\left(-h_{f}=n_{f}+l_{f}-T\right)$, and overall financial expenditures $\left(\mathrm{C}=\mathrm{nqP}_{\mathrm{q}}+\mathrm{P}_{\mathrm{c}} \mathrm{C}_{\mathrm{m}}\right)$,

$$
\frac{\partial \mathbf{X}}{\partial \mathbf{P}^{\prime}}+\frac{\partial \mathbf{X}}{\partial Y} \mathbf{X}^{\prime}, \text { where } \mathbf{X}^{\prime}=\left(-h_{m},-h_{f}, C\right) \text { and } \mathbf{P}^{\prime}=\left(W_{m}, W_{f}, P_{c}\right)
$$

be a symmetric negative semidefinite matrix. ${ }^{3}$ In the context of the demand system (2.3), this reduces to requiring that $L M^{\prime}$ and $L F^{\prime}$ be nonnegative. Given this, one can integrate to derive the money metric indirect utility function

$$
\begin{gathered}
V\left(Y, w_{m}, w_{f}\right)=Y+\int_{0}^{w_{m}} L M(x) \mathrm{dx}+\int_{0}^{w_{f}} L F(x) \mathrm{dx} \\
\text { where } w_{i}=W_{i} / P_{c}
\end{gathered}
$$

\footnotetext{
${ }^{3}$ This is a straightforward application of theorem 8 in Epstein (1981).
} 
and associated household utility function

$$
\begin{aligned}
& U\left(C, h_{m}, h_{f}\right)=C-\int_{0}^{h_{m}} w_{m}(x) \mathrm{dx}-\int_{0}^{h_{f}} w_{f}(x) \mathrm{dx} \\
& \text { where } w_{m}()=L M()^{-1} \text { and } w_{f}()=L F()^{-1} .
\end{aligned}
$$

Household utility is simply given by total consumption expenditures minus the disutility of labour, i.e. the area under the individual labour supply curves.

The preceeding one period model can be extended to a multiperiod lifetime setting by, in the standard macro-theorist's fashion, assuming time separable utility, so that (2.3) and (2.6) represent the period by period household demands and flow of utility. Aggregating (2.6) across all individuals and dividing by the total population, one sees that average utility per capita is given by consumption per capita minus the disutility of labour per capita. If labour supply is of the isoelastic form $h_{i}=\gamma w_{i}^{\varepsilon_{i}}$, per capita utility is then given by:

$$
u=y\left[(1-s)-\left(\frac{\varepsilon_{m}}{1+\varepsilon_{m}}\right) \theta_{L_{m}}-\left(\frac{\varepsilon_{f}}{1+\varepsilon_{f}}\right) \theta_{L_{f}}\right]
$$

where $\mathrm{y}$ is output per capita, s the savings rate, and $\theta_{i}$ the share of each factor in total income. For constant savings rates and factor shares, this justifies the popular fixation on output per capita as a measure of welfare.

To close the model, one must specify the evolution of the macroeconomy and, in particular, the capital stock. Here, any number of frameworks could be used to motivate the savings rate, e.g. overlapping generations with or without actuarially fair market interest rates, intergenerational insurance, and/or accidental bequests. I heroically sweep these issues aside and, following Solow, assume that the savings rate, by some combination of private and public sector behavior, remains fixed. This allows me to focus on the mechanisms emphasized in this paper, 
e.g. fertility and education, and their impact on overall future consumption possibilities. The element left unexamined, the evolution of the savings rate, will determine the ultimate allocation of these consumption possibilities across generations. ${ }^{4}$

\footnotetext{
${ }^{4}$ Thus, one can see the presentation as part of a Ramsey problem in which the planner maximizes the discounted flow of per capita utility by changing national savings and investment through the usual tax and expenditure mechanisms, but with no direct control over household decisions. For appropriate choices of the discount parameter and elasticity of intertemporal substitution, the planner will, in the absence of the epidemic, choose the same initial and steady state savings rate, with some (hopefully minimal) dynamics in between. Taking this as the benchmark, one then evaluate whether the epidemic, overall, increases or decreases future per capita consumption possibilities. The planner's choice of a savings rate during the epidemic then determines the distribution of these consumption possibilities across generations. Since my emphasis is on the impact of the epidemic, and not the appropriate distributional choice across future generations, I do not pursue this further.
} 


\section{Data and Estimation Strategy}

I estimate the model using the microdata files of the South African 1995 October Household Survey (OHS) and the 1998 Demographic and Health Survey (DHS). ${ }^{5}$ The OHS provides a variety of personal and behavioral information on each household member (e.g. age, sex, education, labour force participation, income, fertility, etc), as well as recording recent deaths in the household. Most of the data reported in this survey are consistent with other sources, ${ }^{6}$ but the reported retrospective fertility histories are very low (i.e. appear to involve incomplete reporting) and cannot match the historical population distribution. Thus, I use the DHS, whose primary focus is fertility, to estimate that aspect of behavior. ${ }^{7}$

Estimation proceeds in a simple two-step process: I first use the data of the October Household Survey to estimate incomes as a function of age, sex and education, and then use the predicted relative incomes by educational attainment as the independent variable in the household behavioral equations. Exogenous variation in individual education levels then allows me to identify the price elasticity in each demand equation. I focus only on the behavior of individuals 25 and over, whose education is taken as completed. In the data, however, both fertility and labour supply begin as early as age 12 (albeit, at extremely low levels). The retrospective fertility histories in the Demographic and Health Survey allow me to identify the behavior of fertility

\footnotetext{
${ }^{5}$ The OHS and DHS data sets can be ordered through the websites www.statssa.gov.za and www.measuredhs.com, respectively. The construction of variables from the raw data is explained in the appendix at the end of this paper.

${ }^{6}$ For example, predicted employee earnings (estimated off of interval income data) are just 12 percent below national accounts compensation of employees, while the reported mortality rates provide a good match to long term (1970 to 1996) intercensal cohort survival rates.

${ }^{7}$ Official South African data on births, based upon voluntary registration, are woefully inaccurate. Births can be registered years after the fact. Thus, 238 thousand births were registered in 1991 as occurring in that year, but by the year 2000 the total number of births registered for 1991 had risen to 680 thousand (RSA, SSA 2001b). Yet, the 1996 census found about 960 thousand five year olds (microdata files). The primary incentives for birth registration are medical insurance requirements and access to social welfare benefits, and these do not appear to be sufficient to ensure timely or comprehensive coverage. Official mortality data face similar problems.
} 
at earlier ages, under the assumption that each woman, when young, knew what her final educational attainment would be. For participation, I have only a single cross section, so I simply extend the quadratic age profile estimated off of adults 25 and over.

I estimate both fertility and hours of work using a Poisson count model, where the probability of observing a count value of $y_{i}$ is given by:

$$
P\left(Y_{i}=y_{i}\right)=\frac{e^{-\lambda_{i} \lambda_{i}^{y_{i}}}}{y_{i} !} \quad \text { where } \ln \lambda_{i}=\mathbf{B}^{\prime} \mathbf{x}_{i}
$$

As the expected count is given by $\lambda_{i}$, with a quadratic in age and the ln relative wage as regressors, this produces isoelastic demand and supply functions. The Poisson, while extremely easy to estimate, has the undesirable feature that the variance of the process is equal to its mean. There are also additional potential error correlations posed by sample design (clustering) or the use of panel data (in the fertility equation). However, as shown by Gourieroux et al (1984), provided that the mean of $\mathrm{Y}$ conditional on $\mathrm{x}_{\mathrm{i}}$ is equal to $\lambda_{i}$, maximum likelihood estimates based upon the Poisson distribution are consistent, whatever the process generating the variance of Y may be. Consequently, I use pseudo-maximum likelihood methods, estimating the coefficients using the maximum likelihood Poisson model, but calculating robust standard errors allowing for an arbitrary variance process between observations within survey primary sampling units and across multiple observations for individuals, as well as adjusting for the two-step procedures involved in using parameter estimates from the income equation. ${ }^{8}$ This allows me to simplify the presentation of the results. As a sensitivity test, I have also estimated the various equations using

\footnotetext{
${ }^{8}$ Let $\mathbf{B}_{1}$ and $\mathbf{B}_{\mathbf{2}}$ be the vectors of parameters estimated in the first and second step, respectively, across sample sizes $\mathrm{n}_{1}$ and $\mathrm{n}_{2}$. Further, let $\mathrm{N}$, the union of the two samples, be divided into $\mathrm{M}$ independent clusters $\mathrm{G}_{1}, \mathrm{G}_{2} \ldots \mathrm{G}_{\mathrm{M}}$ and let $l_{i k}$ denote the log likelihood of observation $\mathrm{k}$ in equation $\mathrm{i}$. Then, accounting for the two-step procedure and arbitrary correlation within clusters, asymptotically

$$
\mathrm{n}_{1}^{1 / 2}\left(\hat{\mathbf{B}}_{1}-\mathbf{B}_{1}\right) \sim N\left(0, \mathrm{n}_{1} \mathbf{H}_{11}^{-1} \mathbf{g}_{11} \mathbf{H}_{11}^{-1}\right) \quad \text { and } \quad \mathrm{n}_{2}^{1 / 2}\left(\hat{\mathbf{B}}_{2}-\mathbf{B}_{2}\right) \sim N\left(0, \mathrm{n}_{2} \mathbf{A} \mathbf{B} \mathbf{A}^{\prime}\right)
$$$$
\text { where } \quad \mathbf{H}_{i j}=\sum_{t=1}^{n_{i}} \frac{\partial^{2} l_{i t}}{\partial \mathbf{B}_{i} \partial \mathbf{B}_{j}{ }^{\prime}}, \quad \mathbf{g}_{i j}=\sum_{m=1}^{M}\left(\sum_{k \in G_{m}} \frac{\partial l_{i k}}{\partial \mathbf{B}_{i}}\right)\left(\sum_{k \in G_{m}} \frac{\partial l_{j k}}{\partial \mathbf{B}_{j}{ }^{\prime}}\right), \quad \mathbf{A}=\left[\begin{array}{lll}
\mathbf{H}_{22}^{-1} & -\mathbf{H}_{22}^{-1} \mathbf{H}_{21} \mathbf{H}_{11}^{-1}
\end{array}\right] \quad \text { and } \quad \mathbf{B}=\left[\begin{array}{ll}
\mathbf{g}_{22} & \mathbf{g}_{21} \\
\mathbf{g}_{12} & \mathbf{g}_{11}
\end{array}\right] \text {. }
$$ 
constant, linear and generalized variance-mean ratio negative binomial, as well as generalized event count (Winkelmann \& Zimmermann 1991), cross-section models and, where applicable, random effects poisson and negative binomial panel data models (Hausman et al 1984). ${ }^{9}$ The results, in almost every case, are very similar, and are reported in footnotes.

I depart from the Poisson model in the determination of children's educational attainment, where I used an ordered probit. Less educated women tend to have more children, who are in turn given relatively less human capital. In this sense, the variance of educational outcomes is quite important, as a mean preserving spread in initial educational attainment will lower average educational levels and welfare in the next generation. Furthermore, bad outcomes tend to be perpetuated from one generation to another. This becomes relevant in assessing the impact of the AIDS epidemic, where I will assume that the education of orphaned children is permanently interrupted at the time of their parents' death. I use an ordered probit model, dividing the pop-

The proof is a simple extension of the standard proof of the asymptotic distribution of the one or two step MLE using a first order Taylor expansion (e.g. Davidson and MacKinnon 1993, Murphy and Topel 1985) with the empirical Hessian estimator of the information matrix (which in my sample usually produces substantially larger standard errors than the outer-product-of-thegradient estimator, which is known to understate standard errors in finite samples - Davidson and MacKinnon 1993, p. 477).

${ }^{9}$ With the conditional mean of $\mathrm{Y}_{\mathrm{i}}$ given by $\mathrm{E}\left[\mathrm{Y}_{\mathrm{i}} \mid \mathbf{x}_{\mathrm{i}}\right]=\exp \left(\mathbf{B}^{\prime} \mathbf{x}_{\mathrm{i}}\right)$, in the Poisson model the variance-mean ratio is 1 . In the constant and linear variance-mean ratio negative binomial models, it is given by $1+\mathrm{a}$ and $1+\mathrm{a} E\left[\mathrm{Y}_{\mathrm{i}} \mid \mathbf{x}_{\mathrm{i}}\right]$, respectively. In the generalized event count model it is given by $1+\mathrm{a} E\left[Y_{i} \mid \mathbf{x}_{i}\right]^{\mathrm{k}}$, while in the generalized variance-mean negative binomial model it is given by $1+\exp \left(\mathbf{B}_{2}^{\prime} \mathbf{z}_{\mathrm{i}}\right) \mathrm{E}\left[\mathrm{Y}_{\mathrm{i}} \mid \mathbf{x}_{\mathrm{i}}\right]$ and I use the same set of regressors to determine the variancemean relationship $\left(\mathbf{z}_{\mathrm{i}}=\mathbf{x}_{\mathrm{i}}\right)$. The Poisson and constant and linear variance-mean binomial models are special cases of the generalized event count model, and the generalized negative binomial model subsumes the Poisson and linear variance-mean negative binomial as a special case or limiting distribution. The random effects panel data Poisson and negative binomial models have linear and constant variance-mean ratios (respectively), and take into account each panel member's average realized value of the dependent variable. As is usually the case, the various nonPoisson models do better in predicting the distribution of the dependent variable (e.g. the number of zeros). However, as my emphasis will be on the mean, which is fairly insensitive to the choice of distribution, I opt for the simple Poisson formulation, with robust standard errors. 
ulation into a state space of 14 educational categories based upon individual years of education, ${ }^{10}$ to keep track of the variance of educational attainment and allow poor outcomes to have disproportionate dynamic effects.

\footnotetext{
${ }^{10}$ As detailed in the appendix at the end of the paper.
} 


\section{Estimates}

Table I below presents the estimation of the Beckerian elements of the model. I begin, in columns (1) and (2), by predicting the ln of before and after-tax hourly wages as a function of quadratics in age and education and a dummy variable for sex. ${ }^{11}$ The return to education in South Africa is quite high, with a $234 \%$ increase in ln after-tax incomes associated with a movement from 0 to 16 years of education and a $92 \%$ premium to tertiary education alone. There is also a great deal of variation in educational attainment within the OHS household sample, with $22 \%$ of persons over age 25 having 2 years of education or less and $24 \%$ having 12 years or more. The extraordinary dispersion in educational outcomes and average earnings by

${ }^{11}$ These estimates do not adjust for selectivity bias (see Killingsworth and Heckman 1986). I have run more complicated (joint maximum likelihood) systems, augmenting the wage equations with probit selection equations, where the probability of working is determined by the variables in the wage equation plus marital status, children per adult in the household, and the total number of adults in the household (all interacted with sex, i.e. a separate participation equation by sex). First, the point estimate of the correlation between the error terms in the participation and wage equations is negative, which goes against the standard presumption in this literature (this holds even when I allow sex-based covariance between the errors in the participation equations and the joint wage equation, or when I estimate the entire wage/participation model separately by sex). Second, and more importantly, while the age and sex profiles are somewhat flattened, the educational profile of incomes, which is used to identify the price effects in all the subsequent equations, is virtually unchanged. Consequently, to keep things as simple as possible, I ignore selection issues and estimate relative labour incomes using data on workers alone, as reported above. I should note that the data are interval coded (hence the pseudo-R2) and that I restrict the sample to employees, i.e. exclude the self-employed.

In estimating separate equations for before and after tax hourly incomes, my approach produces an unrealistic linear budget constraint by worker characteristic and, also, implies negative effective tax rates for the least educated young and old age groups. I have run a more realistic model, in which I take into account the non-linearities in the tax code, work opportunities and supply decisions (due to fixed costs, fatigue effects, etc) by modeling participation as a probit zero-one decision subject to a lump sum before and after tax income. I calculate after tax income in two ways, using the tax code and then with a separate regression (mirroring the hourly estimates of Table I). First, I find that the predicted labour supply response to a change in the after tax wage is virtually the same whether I use the tax code or the after tax regression, i.e. the after tax regressions are a close approximation to the actual tax code. Second, the coefficient estimates of the probit model predict that, at current levels, a 1 percent rise in wages will increase the supply of effective male and female labour in the South African sample by .18 and .44 percent, respectively. This is quite close to the Poisson estimates presented in Table I. Since the Poisson constant elasticity functional form allows for easy interpretation of the coefficients and calculation of the disutility of labour, and the linear before and after tax budget constraint avoids the complexity of calculating the tax burden at each level of income during the simulations, I opt for the simplified formulation presented above. 


\begin{tabular}{|c|c|c|c|c|c|c|}
\hline \multicolumn{7}{|c|}{ Table I: Estimation of the Beckerian Elements of the Model } \\
\hline & (1) & (2) & (3) & (4) & $(5)$ & $(6)$ \\
\hline & $\begin{array}{l}\text { Before-tax } \\
\text { ln Wages } \\
\text { per Hour }\end{array}$ & $\begin{array}{l}\text { After-tax } \\
\text { ln Wages } \\
\text { per Hour }\end{array}$ & $\begin{array}{c}\text { Male } \\
\text { Hours } \\
\text { of Work }\end{array}$ & $\begin{array}{c}\text { Female } \\
\text { Hours } \\
\text { of Work }\end{array}$ & Fertility & $\begin{array}{l}\text { Children's } \\
\text { Completed } \\
\text { Education }\end{array}$ \\
\hline Model & $\begin{array}{l}\text { interval } \\
\text { regression }\end{array}$ & $\begin{array}{l}\text { interval } \\
\text { regression }\end{array}$ & Poisson & Poisson & Poisson & $\begin{array}{c}\text { ordered } \\
\text { probit }\end{array}$ \\
\hline age & $\begin{array}{c}.0820 \\
(.0028)\end{array}$ & $\begin{array}{c}.0666 \\
(.0028)\end{array}$ & $\begin{array}{c}.1737 \\
(.0037)\end{array}$ & $\begin{array}{c}.2125 \\
(.0057)\end{array}$ & $\begin{array}{c}.5134 \\
(.0081)\end{array}$ & $\begin{array}{c}.0354 \\
(.0081)\end{array}$ \\
\hline $\operatorname{age}^{2}$ & $\begin{array}{c}-.0008 \\
(.0000)\end{array}$ & $\begin{array}{l}-.0006 \\
(.0000)\end{array}$ & $\begin{array}{c}-.0021 \\
(.0000)\end{array}$ & $\begin{array}{c}-.0026 \\
(.0001)\end{array}$ & $\begin{array}{c}-.0096 \\
(.0002)\end{array}$ & $\begin{array}{c}-.0006 \\
(.0001)\end{array}$ \\
\hline $\mathrm{E}$ & $\begin{array}{c}.0379 \\
(.0044)\end{array}$ & $\begin{array}{c}.0341 \\
(.0042)\end{array}$ & & & & \\
\hline$E^{2}$ & $\begin{array}{c}.0082 \\
(.0003)\end{array}$ & $\begin{array}{c}.0070 \\
(.0003)\end{array}$ & & & & \\
\hline $\operatorname{sex}$ & $\begin{array}{l}-.2190 \\
(.0095)\end{array}$ & $\begin{array}{l}-.1768 \\
(.0094)\end{array}$ & & & & \\
\hline $\begin{array}{l}\text { Wage } \\
\text { Index }\end{array}$ & & & $\begin{array}{c}.1710 \\
(.0078)\end{array}$ & $\begin{array}{c}.4399 \\
(.0134)\end{array}$ & $\begin{array}{c}-.3538 \\
(.0140)\end{array}$ & $\begin{array}{l}1.1382 \\
(.0378)\end{array}$ \\
\hline $\begin{array}{l}\text { year of } \\
\text { birth }\end{array}$ & & & & & $\begin{array}{c}-.0031 \\
(.0013)\end{array}$ & $\begin{array}{c}.0292 \\
(.0016)\end{array}$ \\
\hline HIV & & & & & $\begin{array}{l}-1.633 \\
(.1896)\end{array}$ & \\
\hline constant & $\begin{array}{c}2.932 \\
(.0571)\end{array}$ & $\begin{array}{c}3.225 \\
(.0559)\end{array}$ & $\begin{array}{c}-.0791 \\
(.0781)\end{array}$ & $\begin{array}{l}-1.600 \\
(.1195)\end{array}$ & $\begin{array}{c}-1.847 \\
(2.596)\end{array}$ & \\
\hline $\mathrm{N}$ & 26289 & 25967 & 27253 & 33238 & 171206 & 10135 \\
\hline Pseudo $\mathrm{R}^{2}$ & .1975 & .1810 & .1620 & .1495 & .0551 & .0549 \\
\hline \multicolumn{7}{|c|}{$\begin{array}{l}\text { Notes: Wage Index }=\mathrm{B}_{\mathrm{E}} \mathrm{E}_{\mathrm{i}}+\mathrm{B}_{\mathrm{E} 2} \mathrm{E}_{\mathrm{i}}^{2} \text {, with B's from column (2). } \mathrm{E}_{\mathrm{i}} \text { equals own education in columns (3)-(5) } \\
\text { and mother's education in column (6). Age in column (6) equals mother's age at time of child's birth. HIV is } \\
\text { the historical antenatal clinic HIV seroprevalence rate for the woman's quinqennial age group at that time of } \\
\text { her life. The sample in column (5) is made up of a panel of } 7276 \text { individuals. The construction of the } \\
\text { remaining variables and sample selection procedures are explained in the appendix at the end of this paper. All } \\
\text { standard errors are adjusted for clustering (on enumeration areas or, for (5), on panel individuals) and the } \\
\text { two-step procedure. }\end{array}$} \\
\hline
\end{tabular}


educational group present in South Africa identify the price effects in the demand equations of the model. ${ }^{12}$ I use the coefficients on education in column (2) to construct an index of relative lifetime wages, Wage Index, which is used as an independent variable in the remaining columns of the table. ${ }^{13}$

Columns (3) and (4) of Table I estimate the labour supply response of males and females to a change in the value of their time. As is frequently the case in the labour literature, I find that female labour supply is more elastic than men's. With every $1 \%$ increase in wages, male labour supply rises $.17 \%$ and female labour supply rises $.44 \% .^{14}$ A better sense of the implications of the coefficient estimates is provided by Figures 4.1 and 4.2, where I graph the average hours of work by age group in the prime working years in South Africa and the United States, and then predict the behavior of the United States population using the coefficient estimates of the model. ${ }^{15}$ Average male hours of work between the ages of 20 and 65 are 29.3 in South Africa

\footnotetext{
${ }^{12}$ The reader might be concerned that differences in incomes and economic and social opportunities between racial groups in South Africa bias the model's estimates of behavioral responses to income. In an unpublished appendix, available from the author, I show that while race is a significant determinant of incomes and behavior in South Africa, the inclusion of racial dummies has virtually no impact on the model's estimate of the overall household response to changes in wage income. To keep things as concise as possible, in this paper I focus on the simple model presented above.

${ }^{13}$ The before tax equation is used later in the paper to calculate the effective labour supply, which determines output and wages in general equilibrium.

${ }^{14}$ Alternative distributional assumptions yield mostly similar results. The linear and generalized variance-mean ratio negative binomial models produce male/female wage coefficients of $.17 / .42$ and $.19 / .45$, respectively, while the generalized event count model provides estimates of $.22 / .49$. Only the estimates of the constant variance-mean ratio negative binomial model (.44/.77) differ substantially. However, this model is a restricted version of the generalized event count model and is strongly rejected in the data.

${ }^{15}$ The SA data are the predicted OHS population values. The US data are the 2000 Consumer Expenditure Survey (BLS 2002) population values. To project US behavior, I first use the microdata of the CES to estimate after-tax wages in the US with the same functional form as column (2) of Table I. I then predict the behavior of the CES sample using the coefficient estimates of columns (3) and (4) of Table I, applying a purchasing power exchange rate of 1.74, based upon Penn World Table 6.1 (Heston et al 2002), to convert the year 2000 US dollar wages to 1995 South African Rand. Table I uses the education slope of the wage equation to estimate the supply price response, ignoring the age profile of wages, which is subsumed in the quadratic age term. To predict US behavior, allowing for the slightly different US age profile of incomes,
} 
Figure 4.1: Male Hours of Work

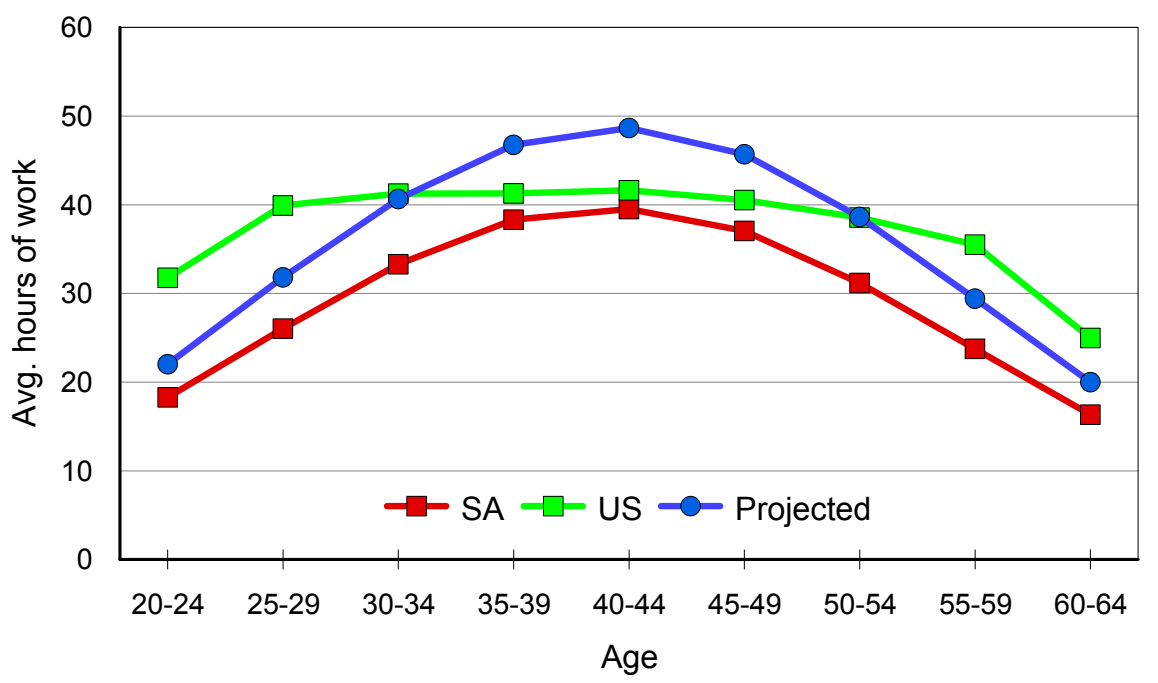

Lifetime: SA 29.3

US 37.3

Projected 36.0

Figure 4.2: Female Hours of Work

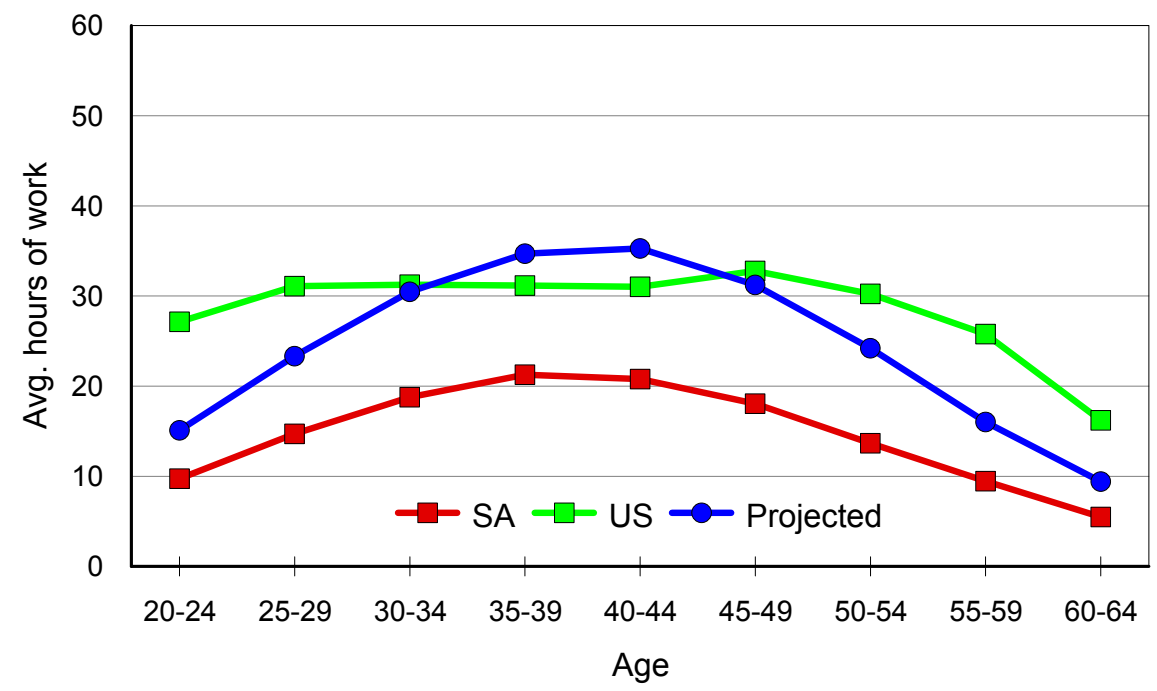

Lifetime: SA 14.7 US 28.5

Projected 24.4 
and 37.3 in the United States. Using US wage values, the model predicts that the United States male population should work an average of 36.0 hours. The model produces a profile of labour supply that is somewhat more hump-shaped than that present in the United States, reflecting patterns seen in South Africa. Part time employment opportunities may be better rewarded in a more service oriented economy, and this structural, demand consideration, might explain the higher relative participation of younger and older age groups, who have lower intrinsic labour supply, in the U.S. economy. ${ }^{16}$ The female labour supply equation produces a similar pattern, predicting a substantial rise in participation, but not quite attaining the levels or shape seen in the US economy. While not perfect, the model does not produce obviously embarrassing results (e.g. predicting 100 hours of work at US income levels).

Column (5) of Table I uses the retrospective fertility histories of the Demographic and Health Survey to calculate the response of fertility to a change in the price of a woman's time. ${ }^{17}$ I include a time trend to account for trends in wages and the price of education. The times series aspect of the DHS data also allows me to measure the impact of community HIV infection on fertility. As shown in the table, I find that the historical HIV infection rate for each woman's quinqennial age group, as recorded in the maternity clinic seroprevalence surveys cited in the

I reinterpret the age specific constant terms to exclude the age profile of wages, which is then captured in the wage supply response term. My choice of CES income variables, samples and weights is described in the appendix at the end of this paper.

${ }^{16}$ Amongst workers aged 29 or less or 55 or more in the South African economy, $90 \%$ worked 35 hours or more. The comparable statistic for the United States CES sample is $67 \%$.

${ }^{17}$ The reader might worry that there is a bit of a logical inconsistency in using a count model to predict births since, as the time interval gets shorter, more than one birth event becomes biologically impossible. However, for the time frame of Table I, i.e. one year, multiple birth events may occur. The frequency of multiple pregnancies in one birth event (twins, etc.) in the South African DHS by age group is almost identical to that reported in US data (except for women over 40 where, perhaps due to fertility drugs, the US numbers are much higher than those reported in South Africa). However, 2/3 of reported multiple birth events within a 12 month period in the South African data do not involve multiple pregnancies, but rather represent children born 9 to 12 months apart. In a high fertility environment, back to back pregnancies are not that rare. I should note that the predicted Poisson probabilities of more than 2 births in a given year are negligible. 
introduction, ${ }^{18}$ has a strong negative effect on predicted fertility. ${ }^{19}$ Figure 4.3 graphs year 1995 and 2000 fertility rates in South Africa and the United States, respectively, and then projects US fertility using the coefficients of the model. ${ }^{20}$ The model comes close to matching both the lifecycle pattern and the overall level of US fertility.

I estimate the parental demand for quality in the upbringing of their children, in column (6) of Table I, by running an ordered probit of the educational attainment of adults aged 25 or more, whose education is completed, on their year of birth (to capture trends in wages and prices) and the wage index and the age at the time of birth of their mothers. Maternal income has a strong effect on realized education. As mother's educational attainment varies from 0 to 16 years, the average educational attainment of a child born in 1970 (aged 25 in 1995) to a 30 year old mother

${ }^{18}$ Thus, for a woman aged 26 at the time of the 1998 DHS, the HIV variable is the infection rate among 25-29 year olds in the year 1997, when the probit examines her fertility history at age 25, the infection rate among 20-24 year olds in 1996, when the probit examines her fertility at age 24 , and so on.

${ }^{19}$ The three negative binomial cross section models all give exactly the same coefficient estimates as column (5) of the table, as each likelihood is maximized at the limiting Poisson distribution. The generalized event count cross section model yields coefficients of $-.35,-.003$, and -1.59 on the Wage Index, year of birth and the HIV seroprevalence rate, which are virtually identical to the Poisson estimates reported in the table. Similarly, the random effects poisson and negative binomial panel models both yield coefficents of -.35, -.003, and -1.65. Absent the time trend and seroprevalence rates, the coefficient on Wage Index is -.38.

As the impact of HIV on fertility plays an important role in the subsequent analysis, it is worth reporting some additional sensitivity checks. Since HIV infection rates may be proxying for a non-linear time trend, I tried including higher order polynomials in time. With a quadratic, the coefficient on HIV falls to -.71, but with cubic or quartic time trends it rises to -2.93 and -2.75 , respectively (in each case, remaining highly significant). Thus, a coefficient of -1.63 is not, for various formulations of the time trend, an extreme possibility.

${ }^{20}$ I fix the time trend at 1995, which is what I use in the later simulations of the South African economy. The actual US data are from CDC (2002), while the SA and US projected values are the predicted OHS and CES sample behaviors, as described in the footnote earlier above. 
Figure 4.3: Fertility by Age Group

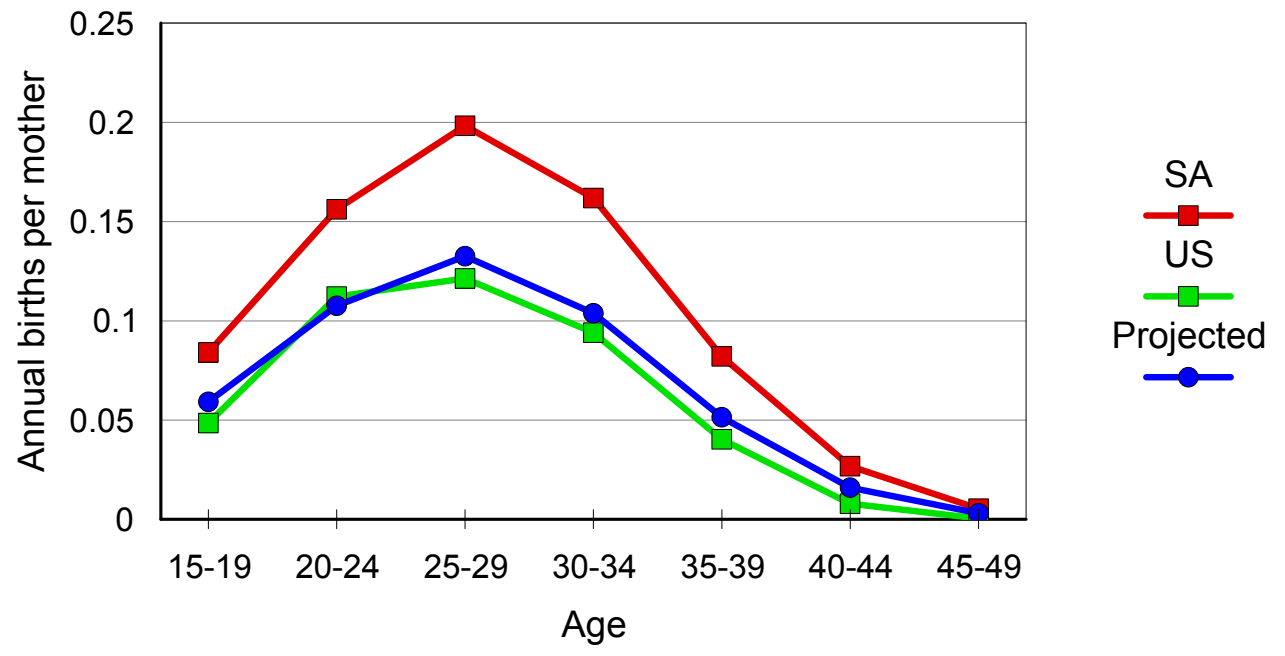

Lifetime: SA 3.57

US 2.13

Projected 2.37 
varies from 7.9 to 14.6 years. ${ }^{21}$ While persons aged 25 and over living with their mothers constitute a somewhat rarified sample in the developed world, raising issues of sample selection, this is not a problem in South Africa, where I am able to identify the mother of about $1 / 6$ of all individuals over 25 and 1/3 of individuals aged 25 to 40. In an unpublished appendix, available upon request, I show that my fertility and education estimates, drawn off of subsamples of the datasets, when applied in a retrospective manner to the OHS female population aged 62 to 99 to predict their surviving children aged 25 to 50, produce an adult population distribution which closely matches the actual size and educational attainment of the 1995 OHS population aged 25 to $50 .^{22}$ Projection to US income levels is somewhat less meaningful in this case, given international variation in both public support of education and the human capital interpretation of a year of education. For what it's worth, individuals aged 25 had an average educational attainment of 9.5 years in South Africa in 1995 and 13.3 years in the United States in 2000. The model's prediction for the 200025 year old US cohort is 13.4 years. $^{23}$

To summarize, the enormous variation in educational attainment and mean incomes by

${ }^{21}$ The same equation run on the wage index of fathers yields a coefficient of 1.06, with average children's attainment going from 8.1 to 14.3 years as their father's attainment varies from 0 to 16 years. I opt for mother's attainment as it is available twice as often as father's attainment. I include a quadratic in mother's age at the time of birth for consistency with the other household demand equations, but its practical impact is not large. For a woman with 12 years of education, children's education attainment ranges from a minimum of 12.1 to a maximum of 12.6 years as the mother's age at the time of birth varies.

${ }^{22}$ The same appendix shows that the non-AIDS mortality estimates (briefly described in the appendix at the end of this paper) are consistent with intercensal mortality rates.

${ }^{23}$ This prediction is based upon the $1 / 5$ of the U.S. CES 25 year old sample for which I can identify mother's education. I set the cohort trend at 1970, matching the value for the 25 year old 1995 South African cohort which I use in the simulations which follow, and adjust 2000 US wages to the 1975 birth year using the 1975-2000 .9\% per annum growth in real, composition adjusted, wages implied by the BLS estimates of the growth of nominal labor compensation minus the growth of effective labour input and the GDP personal consumption deflator (data from http:/www.bls.gov/web/prod3.supp.toc.htm and Council of Economic Advisers 2003). Without adjustment for the trend in U.S. wages, the predicted value is 13.9 years of education. As noted further below, real wage growth in South Africa during the 1970-1995 period is close to zero. 
educational category in South Africa allows me to meaningfully estimate the impact of predictable differences in lifetime income on household decisions. The model matches historical fertility and educational distributions in South Africa and, when projected substantially out of sample, produces patterns of behavior that are not altogether inconsistent with those of the U.S. economy. ${ }^{24}$ In the following section I calibrate the macro-economy to match historical South African data and lay out my assumptions concerning the evolution and behavioral impact of the AIDS epidemic.

${ }^{24}$ In the interest of science, I should note that this should not be interpreted as evidence that the simple demand system I posit, with no cross-price effects, is an accurate description of reality. Since spousal education varies quite closely with own education, the responses reported in Table I really represent the response to a proportional increase in all of the labour prices faced by the household. I confirm this when I estimate cross-price effects, e.g. in the participation and fertility equations, using spousal education, in the fraction of cases where it is available, and find that the sum of the coefficients on both prices is virtually identical to the own price effects reported in Table I. The problem is that the estimates are not naturally consistent, e.g. partner's education has no effect on male labour supply but has a strong effect on female labour supply. To be consistent with utility maximization (i.e. allow calculation of indirect and direct utility functions) the demand system including cross-price effects would have to be severely restricted, reducing to something close to what I report in Table I.

In the table above I have estimated the response to changes in the overall lifetime labour prices faced by households. Since spousal education moves closely with own education, and since I shall be exploring simulations in which the overall level of wages moves up and down for decades at a time, the coefficients reported in Table I arguably provide a good approximation of likely behavior and a proper metric for calculating indirect utility functions, even if their interpretation as pure, contemporaneous, own price effects is something of a fiction. 


\section{Calibration}

I calibrate the macroeconomy using standard aggregate data. I initialize the capital stock using the Federal Reserve Bank of South Africa's estimate of the 1995 capital stock and set the depreciation rate at .06 , the reported ratio of capital consumption to capital for that year. I then fix the Solovian savings rate at .175 , the average real investment to GDP ratio in the period 1946-1995, and set the labour share at .62, the average ratio of compensation of employees ${ }^{25}$ to value added during the same period. I assume a Cobb-Douglas production function in capital and effective labour:

$$
Y=A K^{\alpha} E L^{1-\alpha}, \text { where } E L=\sum_{i} W_{i} L_{i}
$$

Effective labour is given by the sum of labour supplies differentiated by sex, age and education, with fixed relative weights given by my estimates, in column (1) of Table I, of before-tax wages in 1995. I assume a closed economy, with the evolution of aggregate factor returns determined by the unit elastic production function and the domestic supply of capital and labour. ${ }^{26}$ To focus on the role played by changes in factor supplies, I assume zero future total factor productivity growth. ${ }^{27}$

Turning to the HIV epidemic, the South African maternity clinic seroprevalence data presented at the beginning of this paper suggest that overall infection rates had begun to plateau by

${ }^{25}$ Adjusted, using census data, for the implicit labour income of the self-employed.

${ }^{26}$ In the unpublished appendix, I consider the case of perfect capital mobility. This framework excludes most Beckerian effects, as the wage per unit of effective labour is fixed at its initial value. Consequently, the results are similar to the "No Becker" scenario further below where I exclude any endogenous response of household behavior to movements in the wage.

${ }^{27}$ Historical estimates of total factor productivity growth are hampered by the poor quality of South African census data (discussed below), whose coverage is inconsistent and where changes in the questionnaire design have induced large changes in measured participation. For what it's worth, real remuneration per worker grows .3\% per annum between 1970-1995 (http://www.reservebank.co.za), which, after adjustment for rising educational attainment, is suggestive of close to zero growth in effective wages per worker and, by implication, total factor productivity. 
Figure 5.1: HIV Prevalence by Age Group

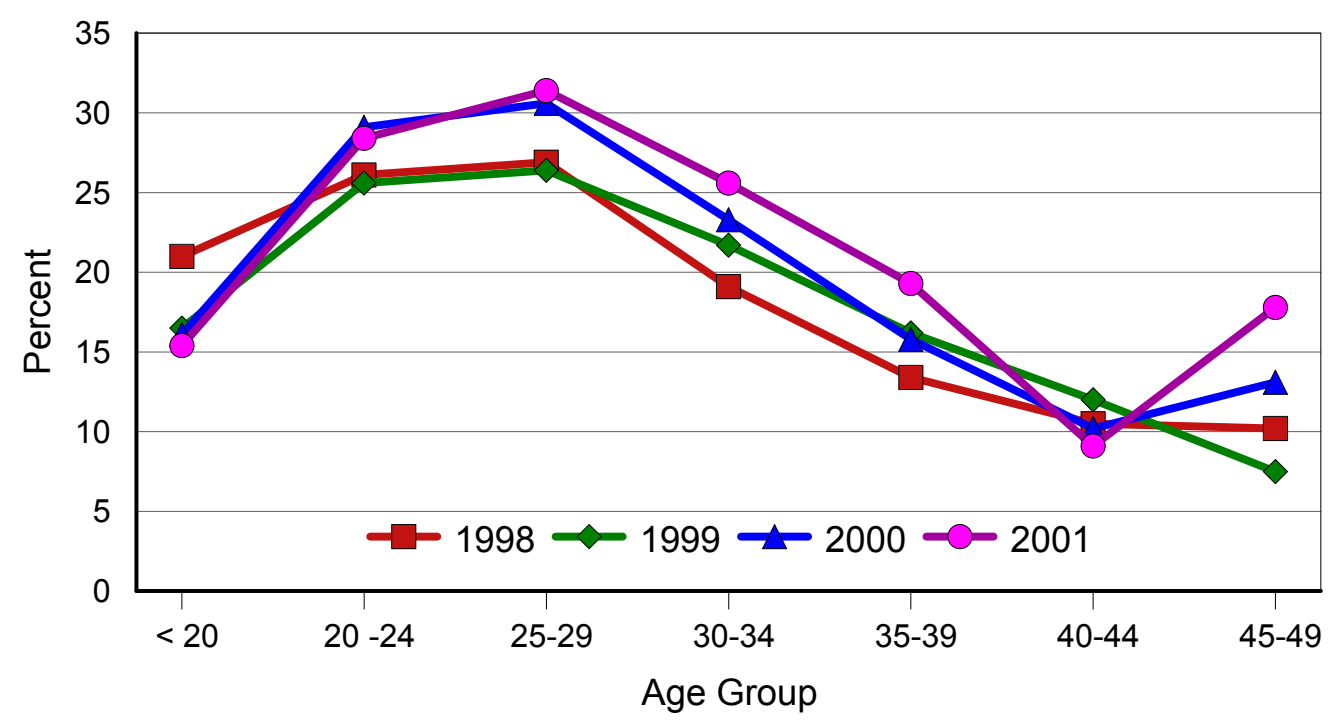

S: RSA, DOH 2001 \& 2002.

Figure 5.2: Cumulative Survival Rates

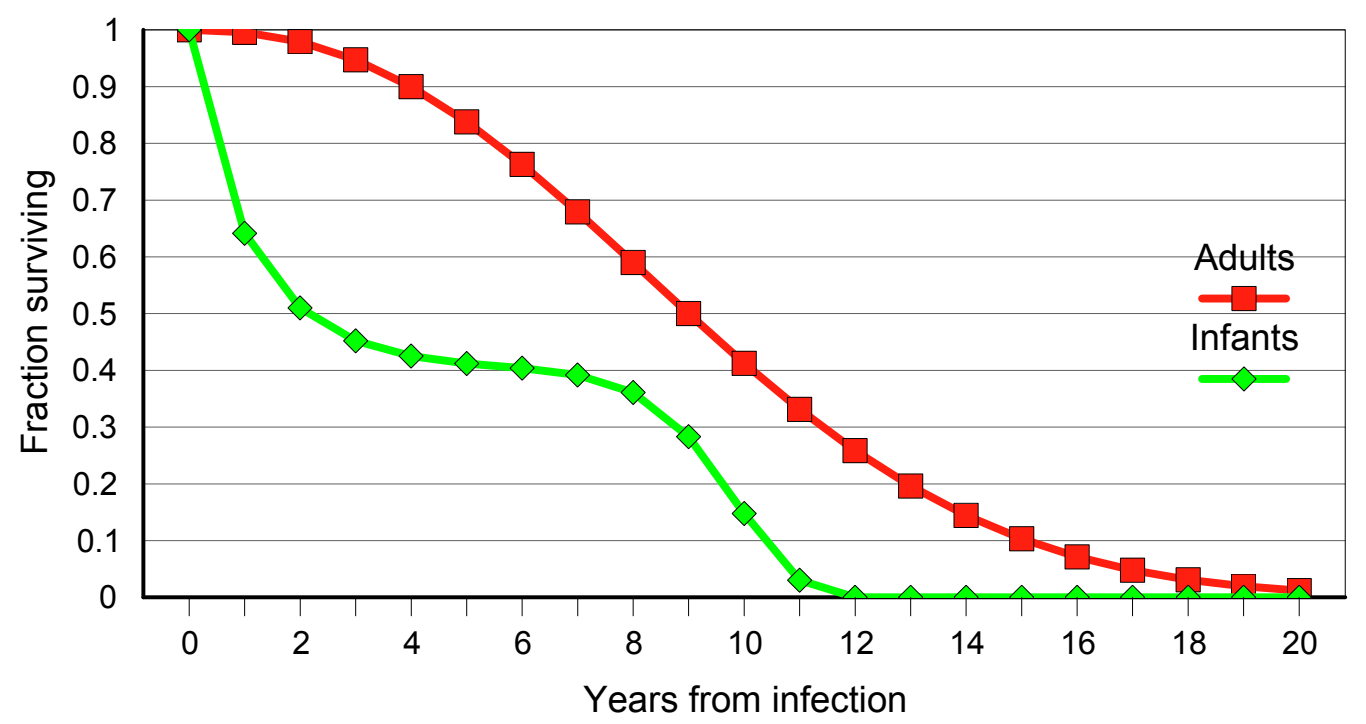

S: UNAIDS 2002. 
the year 2000. Across age groups, infection rates currently peak at ages 25-29 (figure 5.1), and decline thereafter. I interpret the current infection rates of persons over 30 not as random risk, but rather as reflecting the infection of women who, were they 25-29 in 2000, would form part of the current cohort of infected women. It seems reasonable to assume that there is a segment of the population whose interaction with other individuals inevitably, but perhaps unknowingly, leads to infection and that, given the extraordinarily high infection rates already present in the population, the size of this group is given by the maximal infection rate of the 25-29 age group. ${ }^{28}$ Consequently, I assume that new cohorts will experience lifecycle infection profiles similar to the upward sloping part of the 2000 age cross section. I assume that, with medical breakthroughs or behavioral change, post-2000 cohort infection rates decline, sinusoidally, to zero over 50 years. ${ }^{29}$ I also assume that male and female infection rates are evenly matched. ${ }^{30}$ Where avail-

${ }^{28}$ In this, I follow the WHO-UNAIDS modelling recommendations (UNAIDS Reference Group 2002). The UNAIDS Group suggests using aggregate infection rates to estimate the overall "at risk" group and communicability parameters, using an ad hoc procedure to initialize the epidemic. As I need historical age-specific infection rates, I opt for simply using the existing seroprevalence data, with the "at risk" proportion set by the maximal age specific infection rate in 2000 and the lifecycle pattern of infection given by the upward sloping cross section.

${ }^{29}$ Specifically, I begin by smoothing the historical age specific seroprevalence data, running the ln of the infection to non-infection rate (a logit means model) on polynomials in age and year, weighting the observations to account for the heteroskedasticity induced by differing sample sizes. I then use these estimates of cohort age specific infection rates and UNAIDS estimates of HIV survival rates (discussed below) to calculate the cumulative cohort infection for each of the age groups in the cross section in the year 2000. This produces a cross-sectional function S(age) which happens to peak at age 25. I then assume that the lifecycle cumulative infection pattern for future cohorts will be $S^{t}($ age $)=S(\text { age })^{*} \sin \left[(\mathrm{pi} / 2)^{*}(2050-\mathrm{t}) / 50\right]$, where $\mathrm{t} \geq 2001$ is the year in which the cohort begins sexual activity (assumed to start at age 12) and $S^{t}($ age $)=S^{t}(25)$ for all ages $>25$. The last cohort to be infected is that born in 2037, which becomes sexually active in 2049. For cohorts aged 12-24 in 2000, I assume that their lifecycle pattern is given by $S($ age) up to $S(25)$, while for cohorts over 25 in 2000 I assume that their cumulative infection rate rises by $10 \%$ of the gap between their current cumulative infection rate and $S(25)$ each year up to age 39 .

${ }^{30}$ Knowledge of infection rates among men is fairly limited, as the best data on infection rates come from antenatal clinic attendees. However, studies of African couples consistently find that about $30 \%$ to $40 \%$ of male partners of HIV infected females and $30 \%$ to $40 \%$ of female partners of HIV infected males are themselves HIV negative (Carpenter et al 1999, Gray et al 1998, Hira et al 1990, and Serwadda et al 1995). This suggests relatively equal infection rates once the virus spreads to the general community. The Nelson Mandela/HSRC 2002 Household Survey (HSRC 2002), the only large sample community survey of South Africa, found higher 
able, prevalence data indicate fairly equal infection rates across educational groups, ${ }^{31}$ which I shall assume as well.

Regarding mortality, adult individuals infected with HIV typically experience a short period of flu-like symptoms, after which they remain, superficially, asymptomatic, until their immune system collapses and succumbs to opportunistic infections and cancers. ${ }^{32}$ I use the WHO-UNAIDS (UNAIDS Reference Group 2002) recommendations on adult survival times absent retroviral therapy (figure 5.2), which suggest a median survival after infection of 9 years. ${ }^{33}$ While mother-to-child transmission can be reduced through antiretroviral therapy, cesarean delivery and avoidance of breastfeeding, these are all costly and currently about $1 / 3$ of children born of HIV positive mothers in African countries, and South Africa in particular, are infected ${ }^{34}$ a proportion that I assume will remain constant for the foreseeable future. Pediatric AIDS progresses horribly rapidly, with 1/3 of HIV infected South African children dying from the virus within one year of birth (Bobat et al 1999). I use the recommended children's mortality profile of the UNAIDS Group (figure 5.2), which predicts that all infected children die by age 12.

Turning to Beckerian behavior, as HIV infected individuals remain superficially healthy

infection rates among women aged 15-24, but no statistically significant difference between males and females aged 25 and above.

${ }^{31}$ See HSRC 2002, RSA DOH Eastern Cape 2000 and RSA DOH Free State n.d.. Each source shows variation across educational groups, but there is no consistent pattern by educational attainment or across the surveys.

${ }^{32}$ http://www.avert.org/hivstages.htm (11/3/2002).

${ }^{33}$ The UNAIDS Group estimates that retroviral therapy would add about three years to median survival times. In November 2003 the South African government announced it would be distributing free retroviral drugs, but as of March 2004 only 1500 people had received such support, the government had only begun to ask for bids from pharmaceutical companies, and the health minister was extolling the benefits of consuming olive oil, lemon juice and garlic (Goering 2004).

${ }^{34}$ http://www.ama-assn.org/special/hiv/newsline/briefing/mother.htm (11/3/2002), http://www.avert.org/motherchild.htm (11/3/2002), Unicef (2002) and Bobat et al (1999). 
for long periods of time, I assume that adult economic participation and children's education proceeds normally until the final year of each adult's life. ${ }^{35}$ To incorporate the impact of orphanhood, I assume that the education of the surviving children of adults who die of AIDS is interrupted at the moment of their parents' (assumed joint) death. Thus, children borne of parents with HIV will get minimal education, as their parents generally die before they reach 9 years of age, while children whose parents contract HIV after their birth will terminate their education if and when their parents die before they reach 25 years of age. ${ }^{36}$ This almost certainly overstates the impact of the HIV epidemic. Empirical estimates of the impact of orphanhood on children's educational outcomes in Africa range from nil (Lloyd and Blanc 1996) to a 5 to $10 \%$ decline in enrollment rates after the death of each parent (Case et al 2004, Evans and Miguel 2004). ${ }^{37}$ In contrast, my approach results in dual orphaned children born after the year 2005 ,

${ }^{35}$ Morgan et al (2000) report a median survival time from the development of AIDS to death in Uganda of 9.3 months. Thus, the epidemological pattern is one of a prolonged period of apparent health, followed by extremely rapid deterioration and death (see also http://www.avert.org/hivstages.htm, 11/3/2002).

${ }^{36}$ To incorporate this effect, I use the OHS to estimate an additional ordered probit educational equation, representing attainment at ages 6-24 as a function of a quadratic term in age and the mother's wage index (interacted with the quadratic in age). Individuals who reach age 25 without their parents dying from AIDS are endowed with their full human capital, as determined by column (6) in Table I earlier.

${ }^{37}$ Lloyd and Blanc, using cross-section data for seven countries, conclude that family networks make up for the loss of a parent, as they find that orphanhood generally leads to a slight decline in enrollment, but produces both positive and negative effects (depending on the country) on completed attainment, with almost all results being statistically insignificant (their table 8). Evans and Miguel, using panel data for Kenya, report a 2.6 to 3.7\% decline in school participation post-parent death in samples with 85 to $92 \%$ participation rates, but the total effect rises to about an $8 \%$ decline when leads and lags on parental death are included (their figure 1 and tables $1 \& 4$ ). Case et al, using cross sectional data for 10 African countries, report from 3.8 to $4.9 \%$ declines with the death of a single parent and between a 12.1 to $15.2 \%$ decline with the death of both parents in a sample with a mean enrollment rate of $66 \%$ (their table 3 and p. 21). Case et al show an increased effect with the death of both parents, but Evans and Miguel do not find a negative interaction.

For my part, runing a probit of current school attendance in the OHS data on a quadratic in age, district dummies and the survival status of each parent for individuals 6 to 24 , I find that the death of both parents reduces the average annual attendance rate from .77 to .70 (no significant negative interaction). South African data on attendance are not synonymous with achievement, as there is frequent repetition of grades (see Strauss 1999). As an alternative measure, I run an ordered probit of educational attainment on age, district dummies and the survival status of each 
whose parents die early in their life, acquiring only 1/5 of the years of education of non-orphaned children. ${ }^{38}$ Nevertheless, I take this extreme assumption as a baseline, a maximal bound on the conceivable losses of human capital due to the epidemic. ${ }^{39}$ As an alternative, I also consider the possibility that orphanhood has no impact, whatsoever, on the realized education of children.

Reality lies somewhere between these extremes, although the empirical literature on orphanhood and recent trends in South African enrollment (see Section VII) suggest that the path of the epidemic may end up being closer to the no impact scenario.

With regards to fertility, HIV is well-known to be a sexually transmitted disease and, consequently, community wide infection should lower the demand for unprotected sexual activity and, by extension, children. This is confirmed in Table I's estimates, earlier, of the impact of

parent for individuals 15-19 and 20-24 in the OHS, finding that the death of both parents reduces educational attainment an average of .6 years (from 8.6 with dual survival) for the 15-19 age group and .9 years (from 9.9 with dual survival) for the 20-24 age group. Both procedures suggest that about $10 \%$ of cumulated years of education are lost with the death of both parents.

${ }^{38}$ Children born prior to 2005 do somewhat better, with, for example, the 1995 orphaned birth cohort getting half of the years of education of non-orphaned children. Early on, as the epidemic is still spreading, the average parent becomes infected at an older age so their children have the opportunity to acquire more human capital.

As noted in an earlier footnote, there is considerable discordance in the HIV status of couples, so that educational losses are likely to be more spread out than my assumption of dual orphaning allows. This is difficult to model, however, as spouses sero-convert over time (Carpenter et al 1999, Hira et al 1990, and Servwadda et al 1995 find between 5\% and 25\% sero conversion among healthy spouses within a year), so that the final degree of dual vs. single orphaning is difficult to predict. I opt for assuming that all AIDS induced adult deaths produce immediate dual orphans.

${ }^{39}$ One might argue that, aside from the issue of orphanhood, the epidemic will reduce the demand for human capital as the expected return from educational investments is reduced by the shortened expected lifetimes of the current youth. This view, however, is rejected by Section VII's data on continued school enrollment. In that sense, the data are supportive of this paper's rather narrow view of education, at least at the levels seen in Africa, as being primarily a parental consumption good, without substantial regard for economic return. 
age specific community infection rates on fertility. ${ }^{40}$ I use these estimates to modify fertility, with diminishing force as the epidemic wanes and community infection rates decline. The decline of fertility associated with the HIV epidemic plays an important role in the simulations, raising the capital-labour ratio faced by future cohorts and offsetting the reductions in human capital brought about by premature parental death. Although recent South African demographic data support my estimates of the impact of HIV on fertility (see Section VII), I will also consider simulations in which HIV has no impact on fertility, highlighting the important role played by this variable.

Finally, I should note that in all scenarios I shall assume a constant savings rate. The assumption of a constant savings rate allows me to focus on other factors I believe are critical, such as the change in fertility and the possible loss of educational capital. Further, while the South African investment to GDP ratio has fluctuated, it shows no trend, either in the historical past or during the first decade and a half of the epidemic (see Section VII below). Finally, future movements in the savings rate are best thought of as allocations across generations in the consumption possibilities engendered by the epidemic. I take as my baseline simulation of the positive evolution of the economy with HIV the assumption, consistent with current empirical trends and convenient for exposition, that, whatever the private determinants of savings, government policies will adjust so as to distribute these consumption possibilities intergenerationally on the

${ }^{40}$ These estimates, perforce, did not distinguish between behavioral or physiological responses. A growing body of field research (e.g. Gray el al 1998, Carpenter et al 1997 and Hunter et al 2003) indicates that HIV may reduce the fertility of women who are otherwise mostly asymptomatic and unaware of their infectious status by about 50\% (explanations focus on amenorrhea and early term miscarriages). This physiological response, however, is not large enough to explain the estimates of Table I, which suggest that, at a 100\% population infection rate, fertility would be about $20 \%$ of normal. One can interpret this difference as representing an external effect, i.e. the impact of community infection on individual behavior. I have explored various simulations in which I parse Table I's estimates into physiological and behavioral effects, and found that the aggregate results are quite similar to the simple specification of a common behavioral response. To keep the analysis simple, I focus on that interpretation in this paper. An unpublished appendix, available from the author, reviews the literature on the physiological impact of HIV on fertility and presents the alternative simulations. 
basis of a constant savings rate. However, putting aside that particular savings path, I will ultimately show that the epidemic allows all future surviving generations to enjoy higher living standards, while still leaving ample resources to support the infirm. This is the central point of the paper. 


\section{Simulation}

In the pages that follow I simulate the evolution of the South African economy under a variety of circumstances. I consider five scenarios: (1) "No HIV" - the path taken absent the epidemic; (2) "HIV" - the economy with the HIV epidemic; (3) "No Becker" - the economy with the epidemic, but with no endogenous response to changes in wages, i.e. all education, fertility, and participation decisions by educational class kept at their values along the No HIV path; ${ }^{41}$ (4) "No Fertility" - the No-Becker scenario, but with the added dimension that HIV does not have the negative effect on fertility estimated earlier in section IV; and (5) "Full Education" - the HIV path, but without the assumption that children's education is interrupted at the time of their parents' death. The components and assumptions that enter into the simulations are summarized in Table II. Before delving into economic calculations, it is worth recalling the human cost of the epidemic which, as shown in Figure 6.1, could cumulatively claim 18 millions lives (in the baseline HIV scenario). What follows is a statement about economic conditions and the welfare of survivors, not about the desirability of the wholesale slaughter of innocents.

I begin by describing the development of the closed economy. Figure 6.2 below depicts the evolution of the wage per unit of effective labour. Absent the HIV epidemic, the wage initially declines, as better educated young cohorts put pressure on the ratio of capital to effective workers, but eventually begins to climb, as higher levels of education lead to lower fertility and population growth. This pattern is reversed by the epidemic, as high mortality in the first decades of the 21 st century drives up the wage, which then comes back down as the epidemic wanes and the labour force is built back up. In the baseline HIV scenario, the wage rises to 11 percent above the No HIV path by 2040. Although most of the mortality associated with the epidemic is resolved by 2040 (figure 6.1), it takes some 60 years for the wage to return to the No HIV transition path, as the reduced fertility brought about by the changed population structure

${ }^{41}$ This simulation still contains Beckerian effects in that changes in the distribution of educational attainment lead to changes in average behavior and the behavior by educational class responds to the value of the real wage along the No HIV path. 
Figure 6.1: Cumulative AIDS Deaths

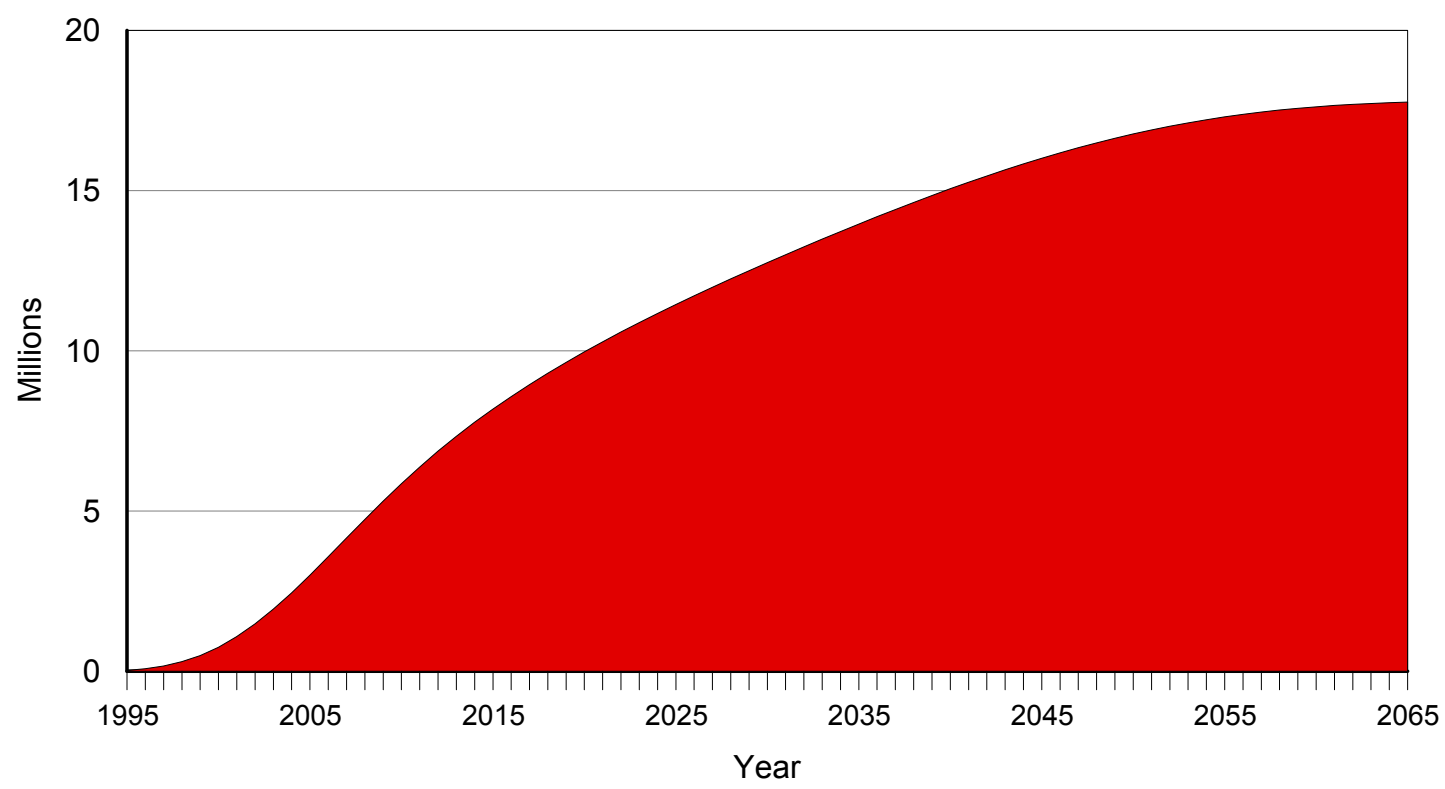

Figure 6.2: Wage per Unit of Effective Labour $(1995=1)$

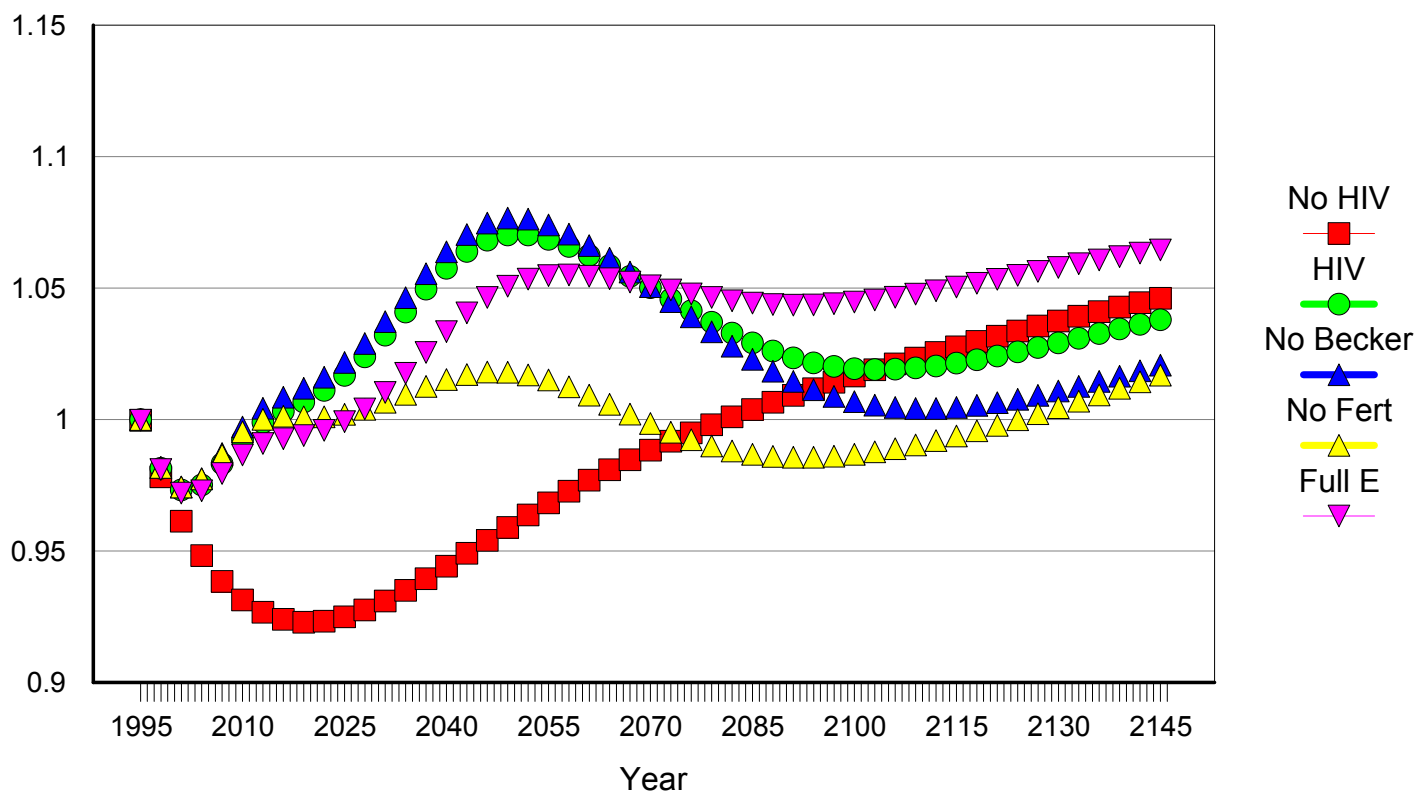




\begin{tabular}{|c|c|}
\hline $\begin{array}{l}\text { No } \\
\text { HIV }\end{array}$ & $\begin{array}{l}\text { Household behavior (participation, fertility, and final educational attainment of } \\
\text { newborn children) from } 1995 \text { on determined by current wages using equations of } \\
\text { Table I (with time trends fixed at } 1995 \text { values). } 1995 \text { population initialized using } \\
\text { OHS adult distribution (age } \geq 25 \text { ), with number and ultimate educational attain- } \\
\text { ment of pre-existing youth cohorts projected from historical household equations } \\
\text { (including pre-1995 time trends). Capital stock initialized using national } \\
\text { accounts data and evolving in accordance with a fixed savings rate. Wages } \\
\text { determined in general equilibrium by capital and labour supply. Mortality given } \\
\text { by pre-AIDS mortality estimates, discussed in the appendix. }\end{array}$ \\
\hline HIV & $\begin{array}{l}\text { Same as No-HIV, except that fertility is lowered to include the impact of current } \\
\text { HIV infection rates on community fertility (as estimated in Table I), while educa- } \\
\text { tion, including the ultimate attainment of pre-existing } 1995 \text { youth cohorts, is } \\
\text { modified under the assumption that human capital accumulation ceases at the } \\
\text { time of parental deaths due to AIDS. HIV infection rates decline to zero over } 50 \\
\text { years, as summarized in footnote } 29 \text { earlier. HIV survival rates given by figure } \\
5.2 \text {, with AIDS and non-AIDS mortality assumed to be independent. }\end{array}$ \\
\hline $\begin{array}{l}\text { No } \\
\text { Becker }\end{array}$ & $\begin{array}{l}\text { Same as HIV, except that wages present along the No-HIV path are used as the } \\
\text { input in determining household behavior, i.e. no endogenous response to realized } \\
\text { wages. }\end{array}$ \\
\hline $\begin{array}{l}\text { No } \\
\text { Fertility }\end{array}$ & Same as No Becker, except that HIV does not influence community fertility. \\
\hline $\begin{array}{c}\text { Full } \\
\text { Education }\end{array}$ & $\begin{array}{l}\text { Same as HIV, except that orphans do not suffer loss of educational capital (at- } \\
\text { tainment equals the demand of parents at time of children's birth). }\end{array}$ \\
\hline \multicolumn{2}{|c|}{$\begin{array}{l}\text { Note: }(*) \text { The number and educational attainment of individuals less than } 25 \text { in } 1995 \text { has to be proj- } \\
\text { ected because the OHS underenumerates youth and because the ultimate educational attainment of pre-existing } \\
\text { youth cohorts is unknown and needs to forecasted (including adjustment for their eventual orphaning in the } \\
\text { HIV scenarios). }\end{array}$} \\
\hline
\end{tabular}

and higher wages sustains a higher capital labour ratio. In the No Becker scenario, the failure of fertility to respond to temporarily higher wages results in a more rapid decline in the wage, which ultimately falls below the levels achieved along the No HIV path. When, in addition, the HIV epidemic has no impact on fertility, the wage falls well below the No HIV transition path. Finally, in the Full Education scenario, the high wages brought about by the epidemic are completely self sustaining. High wages lead to lower fertility and better educated children, which in turn sustain higher wages. 
The impact of the epidemic on the accumulation of human capital is summarized in Figure 6.3, which depicts average educational attainment by cohort birth year. In the HIV, No Becker and No Fertility scenarios, I assume that the orphaning of children leads to an immediate and permanent interruption of their education. As shown in the figure, this lowers the educational attainment of the 1995 cohort by about one and a half years and substantially reduces the human capital of cohorts for the next 100 years. ${ }^{42}$ Uneducated individuals have higher fertility and less educated children, so the losses from orphaning early in the epidemic persist for generations. The positive effect of higher wages on the demand for quality in children and the lower fertility of HIV infected cohorts work against this effect. Consequently, the reductions in educational attainment are smaller in the HIV scenario than they are in the No Becker or No Fertility scenarios. The loss of human capital explains why the wage along the No Becker and No Fertility paths, shown earlier in Figure 6.2, falls below the original, No HIV, transition. Lower educational attainment, for a given real wage per effective worker, leads to higher average community fertility, which drives the real wage down, perpetuating low levels of education and further high fertility. In contrast to the above, in the Full Education scenario I assume that the death of parents does not interrupt their children's education. In this case, the rise in the wage (figure 6.2), leads to higher demand for children's education, which in turn supports continued lower fertility, sustaining both wages and the level of educational attainment.

Figure 6.4 graphs the GDP per capita realized along the various epidemic paths relative to

\footnotetext{
${ }^{42}$ About $1 / 4$ of all HIV free (i.e. surviving) children born in 1995 are orphaned before completing their education, with the ratio falling to $10 \%$ and 5\% for the cohorts born in 2020 and 2045, respectively. The education acquired by orphaned children depends upon how long their parents survive. Children born in 1995 who are eventually orphaned get about 1/2 of the years of education of non-orphaned children, as the epidemic in 1995 was still spreading and much of the adult population was as yet uninfected. Orphaned children born after the year 2005, when the epidemic is established and on-going, get only about $1 / 5$ of the education of non-orphaned children.
} 
Figure 6.3: Educational Attainment by Birth Year

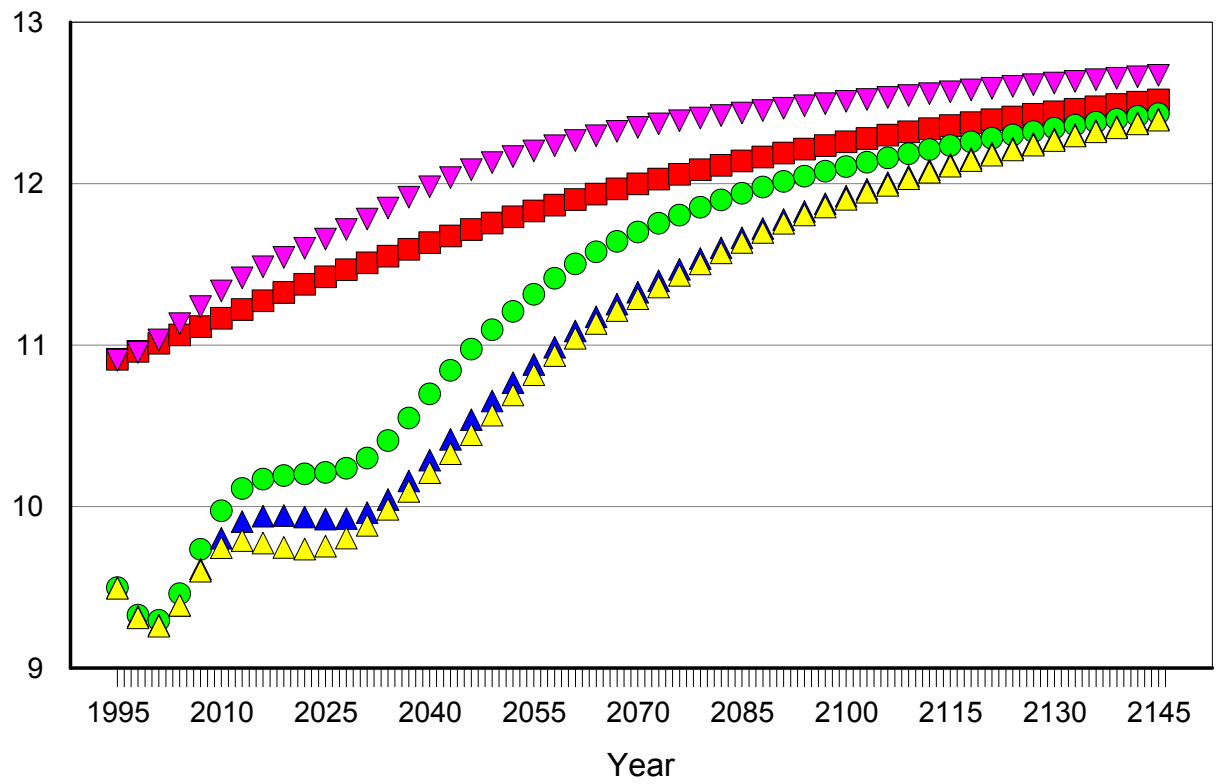

No HIV

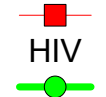

No Becker No Fert

Full E

$\rightarrow$

Figure 6.4: GDP per Capita (relative to No HIV)

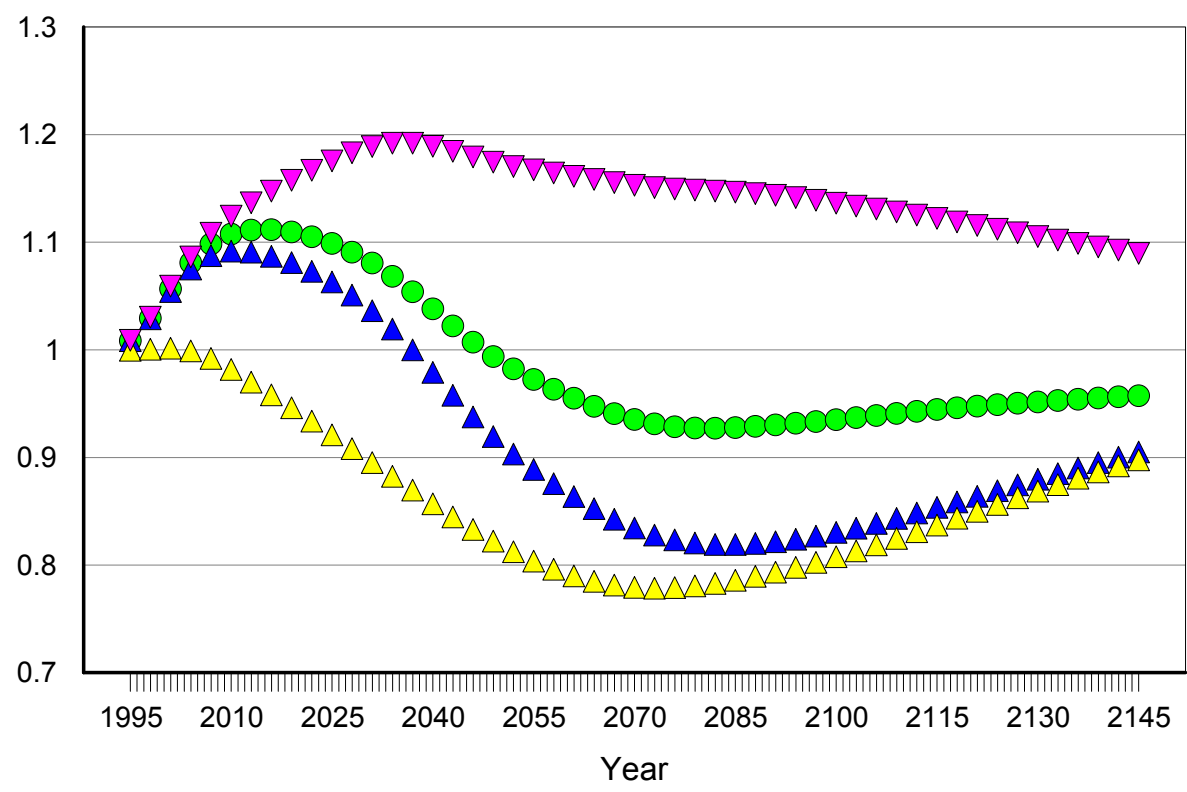

HIV

$$
\text { - }
$$

No Becker

No Fert

Full E

$\nabla$ 
the levels sustained along the No HIV transition to the steady state. ${ }^{43}$ In the baseline HIV simulation, the initial rise in the wage per effective worker more than offsets the losses in cohort educational attainment, so that output per capita remains, for some 50 years, above the No HIV path. Eventually, however, the reduced educational attainment becomes dominant and output per capita falls slightly below the No HIV path. In the No Becker scenario, neither participation, fertility nor children's education respond to the high temporary wages, so output per capita rises by less during the wage boom and then falls considerably below the No HIV path, as the economy is burdened by large uneducated cohorts. Conditions are worse in the No Fertility case, where, despite the wage boom, rising dependency ratios, brought about by adult mortality combined with continued fertility, drag the economy down from the very beginning. In this case, high fertility in an uneducated population ultimately leads to an output per capita about $3 / 4$ of what would have been experienced absent the epidemic. At the other extreme, in the Full Education scenario, with no adverse effects on children's education, high wages and low fertility lead to higher output per capita everywhere along the path. Although this scenario seems decidedly Panglossian, it is not far removed from recent developments in the South African economy where, as discussed in the next section, the epidemic, at least in its early stages, appears to have been associated with falling fertility and sustained human and physical capital accumulation.

Figure 6.4 provides some insight into the influence of the HIV epidemic on future living standards under a fixed savings rate. Rather than consider different intergenerational allocations driven by different savings scenarios, one might broadly summarize the impact of the epidemic

${ }^{43}$ Absent the epidemic, GDP per capita rises $.8 \%$ per annum for the first century, in the gradual transition to a steady state 3.5 times greater than its value in 1995. As the real wage per effective worker rises only $10 \%$ in the transition to the steady state, almost all of this growth is driven by the accumulation of labour, and not capital. The transition is driven by increases in educational attainment, as better educated cohorts raise better and better educated offspring. Higher levels of education increase effective labour per capita directly, through productivity, and indirectly, by raising age specific participation rates and lowering fertility, which in turn shifts the population structure in favour of age groups with higher participation. The steady state involves an average adult educational attainment of 13.0 years, well above the cross sectional average of 8.5 in 1995 . 
on future consumption possibilities by answering the following question: Allowing the savings rate to vary as necessary, what percentage increase, relative to the No HIV path, in future living standards (taken as per capita consumption minus the disutility of labour supply) ${ }^{44}$ is possible under the different scenarios $?^{45}$ The answer to this question is given in the first column of Table III. Starting with the Full Education scenario, one sees that a 6.6 percent increase in living standards in perpetuity is possible. The early booms of the baseline HIV and No Becker scenarios are followed in later years by a relative decline in GDP per capita (figure 6.4), as the reduction in human capital takes its toll. Nevertheless, with an appropriate increase in savings early on these two scenarios allow for 5.6 and 4.3 percent increases in perpetuity, respectively, relative to the No HIV world. Finally, in the case of the No Fert scenario, output per capita begins to decline immediately and there is no boom that can be invested. In this case, an immediate and permanent 3 percent reduction in living standards allows the economy to distribute the severe troth of later years evenly across all generations.

While the preceeding calculations focus on the welfare of the living, one might also consider the support of the dying. In the second column of Table III I calculate the maximum annual expenditure on retroviral therapy for AIDS patients possible consistent with providing all living individuals, everywhere along the path, with the alternative future No HIV living standards. In this calculation, I follow UNAIDS (2002) and assume that retroviral drugs will extend the life of terminal AIDS patients by three years, i.e. each patient receives three years of

\footnotetext{
${ }^{44}$ As noted in section II, this is equal to the flow of per capita utility absent the HIV epidemic. One should hesitate to use this term for the epidemic, as it does not take into account disutility from mortality risk and the modification of behavior (e.g. reduction in fertility) brought about by the presence of this risk. While one could use assumptions and modelling structure to calculate "compensations" for these factors, I think it more reasonable to simply talk about living standards. For generations that live after the epidemic, this is equivalent to utility, given the demand functions estimated in this paper.

${ }^{45}$ This calculation is done subject to the transversality condition that in the new steady state the capital labour ratio permanently sustains the new level of consumption.
} 


\begin{tabular}{||c|c|c||}
\hline \multicolumn{3}{|c||}{ Table III: Alternative Consumption Possibilities } \\
\hline & $\begin{array}{c}\text { Percentage Increase in Living } \\
\text { Standards in Perpetuity }\end{array}$ & $\begin{array}{c}\text { Retroviral Expenditures per } \\
\text { AIDS Patient (2004 US\$) }\end{array}$ \\
\hline Full Education & 6.6 & $\$ 11000$ \\
HIV & 5.6 & $\$ 8800$ \\
No Becker & 4.3 & NA \\
No Fert & -3.0 & \\
\hline \multicolumn{2}{|c|}{$\begin{array}{c}\text { Notes: NA - not applicable, as it is not possible to support a retroviral programme while } \\
\text { maintaining the living standards of the No-HIV path. }\end{array}$} \\
\hline
\end{tabular}

treatment. I assume that these persons do not contribute in any way to economic activity, but count in the total population numbers so that, in addition to retroviral drugs, they receive the average per capita flow of consumption. The number of persons receiving retroviral therapy peaks at around $3.4 \%$ of the population in 2008 and remains above $1 \%$ until 2040. As shown in the table, per patient retroviral expenditures close to 10 thousand US dollars per year are sustainable, while giving both survivors and the invalided the living standards they would have enjoyed absent the epidemic. ${ }^{46}$ To put these numbers in perspective, generic triple dose retroviral therapy drugs are available for US\$292 or less per year. ${ }^{47}$ Brazil's large scale retroviral programme, with auxiliary CD4, viral load and drug resistence testing, is currently delivered at a cost of less than

${ }^{46}$ I convert rand values to US dollars using an exchange rate of 6.5 rand to the dollar, reflecting the value of the rand in the middle of 2004.

${ }^{47} \mathrm{McNeil}$ (2004) reports figures of US\$292 and US\$244 for Indian generic producers and notes that in October 2003 the Clinton foundation negotiated a price of US\$140 per patient year for large orders paid in cash. 
US\$1200 per patient year. ${ }^{48}$ Clearly, the AIDS epidemic endows the South African economy

with enough resources to both care for the victims of the epidemic and still have means left over to raise the standard of living of future generations. ${ }^{49}$

${ }^{48} \mathrm{http} / / / \mathrm{www}$.avert.org/aidsdrugsafrica2.htm (5/16/2004) and Marins et al 2003. Median survival times in Brazil rose from 18 months for AIDS patients diagnosed in 1995 to 58 months for AIDS patients diagnosed in 1996, when the free retroviral programme was instituted (Marins et al 2003). The effectiveness of retroviral therapy improves with expenditure on auxiliary testing, treatment and supervision. Consequently, the UNAIDS assumption of three year survival might be unduly pessimistic for a sufficiently well funded programme, implying that the maximal expenditures calculated above are overestimates of sustainable expenditures per surviving patient. This, however, only reinforces the point made in the table, i.e. that sufficient resources exist to improve the circumstances of infected individuals without harming future generations.

${ }^{49}$ An unpublished appendix, available from the author, reviews the sensitivity of the results to some of the underlying assumptions. Allowing for perfect capital mobility (removing the closed economy assumption), fixes the wage and eliminates most of the Beckerian effects, producing per capita income results similar to the No Becker scenario. Capital mobility, however, eases intertemporal substitution, allowing the economy to sustain somewhat higher permanent increases in living standards (or smaller declines in the No Fert scenario). Reconsidering Table I's estimates of the reduction in fertility brought about by HIV as being a combination of behavioral and physiological (in infected women) influences produces fairly similar results to those shown above. Although this view is completely rejected by the HSRC 2002 community survey, I also consider the possibility that underlying community infection rates are almost double those indicated by the maternity clinic seroprevalence data. In this case, the results are worse, producing more orphans and considerably greater numbers of prospective patients, but the economy can still sustain retroviral expenditures of US\$3100 per AIDS victim per year. 


\section{Empirical Developments}

Recent empirical trends in the South African economy support the analytic assumptions of the simulations laid out above and their positive view of the welfare of future, post-epidemic, generations. Although gross national saving and fixed capital formation were definitely lower in the 1990 s than earlier decades (figure 7.1 ) ${ }^{50}$ this cannot be attributed to the epidemic, as the decline occurred in the late 1980s, long before HIV took root in South Africa. During the 1990s and into the early part of the new century, as the epidemic spread and entered the public consciousness, aggregate savings and capital formation have remained remarkably steady. ${ }^{51}$ During the same period, despite rising parental mortality, ${ }^{52}$ school enrollment rates for the youngest age groups have not fallen, while those of older teenagers have declined by only $5 \%$ (Table IV),

${ }^{50}$ The data in the figure are based upon national accounts aggregates, available from http://www.reservebank.co.za, with public sector saving defined as general government saving plus fixed capital consumption and "private sector" saving defined as household and corporate saving (including public corporations), plus the fixed capital consumption of private business enterprises and public corporations. Together, these equal gross national saving or, equivalently, gross capital formation plus the current account. The savings data are in current prices and gross fixed capital formation is in constant 1995 prices.

${ }^{51}$ As the reader can see, public sector savings during this period rose (from negative to positive), while "private sector" savings (including public corporations) fell. From the point of view of understanding savings behavior, it is interesting to argue whether private savings fell in response to the epidemic or in response to the increase in public savings, or whether public savings rose in response to the decline in private savings. However, from the point of view of the implications for future generations, it does not matter what combination of public or private savings behavior produces a constant national savings rate. It is sufficient that it is simply constant. Hence, the Solovian assumption made in this paper.

${ }^{52}$ Official South African mortality data are seriously undermined by underreporting and unusual administrative procedures. The reporting of deaths is voluntary, motivated by the need for an official burial permit (necessary only in urban areas) or insurance and welfare benefit claims, and is believed to be largely incomplete (RSA SSA 1997 and 2000). Deaths are recorded years after the fact and, historically, published data only indicated the number of deaths reported within a given year, and not the year of occurrence. Further, the Department of Home Affairs allowed forms coming in after December to be added to the December process month for arbitrary periods of time (e.g., the microdata files for recorded deaths 1996 reveal that 97 thousand of the 327 thousand recorded deaths for 1996 were processed in "December"), confounding any analysis of the annual series. For the 1997-2000 period, recorded deaths have recently been reported in a cumulative fashion, based upon year of occurrence (RSA SSA 2001a). As cumulated up to 2001 , these data indicate a $50 \%$ to $100 \%$ increase in the number of male and female deaths in the 25-34 age group from 1997 to 2000 alone. 
Figure 7.1: Saving \& Investment/GDP

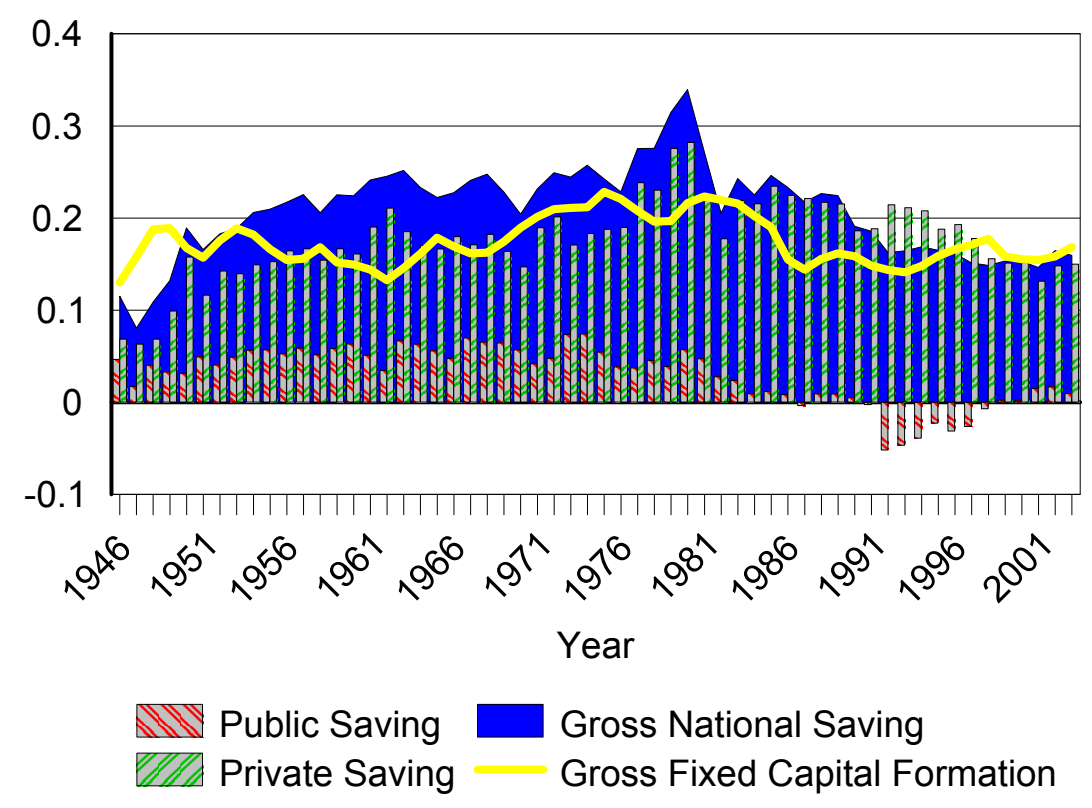

S: http://www.reservebank.co.za.

Figure 7.2: Census Population

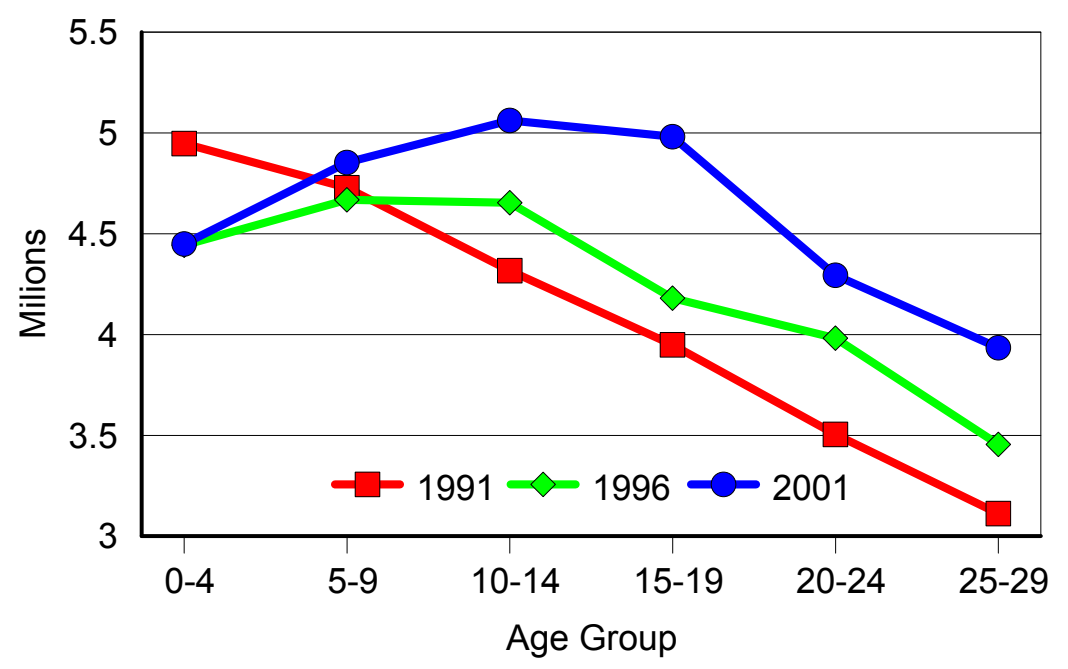

S: RSA CSS 1992, RSA SSA 2004c. 


\begin{tabular}{|c|c|c|c|c|c|c|}
\hline \multicolumn{7}{|c|}{ Table IV: School Enrollment and Orphanhood Rates } \\
\hline & \multicolumn{2}{|c|}{ School Enrollment } & \multicolumn{2}{|c|}{ Maternal Orphan } & \multicolumn{2}{|c|}{ Paternal Orphan } \\
\hline & Ages 7-15 & Ages 16-20 & Ages 7-15 & Ages 16-20 & Ages 7-15 & Ages 16-20 \\
\hline OHS $1993^{*}$ & .95 & .72 & & & & \\
\hline OHS 1994 & .96 & .75 & & & & \\
\hline OHS $1995^{\#}$ & .97 & .76 & .034 & .057 & .14 & .21 \\
\hline OHS 1996 & .96 & .77 & .026 & .045 & .12 & .18 \\
\hline OHS 1997 & .94 & .77 & .032 & .055 & .13 & .20 \\
\hline OHS 1998 & .93 & .74 & .032 & .054 & .12 & .20 \\
\hline OHS 1999 & .95 & .74 & & & & \\
\hline GHS 2002 & .97 & .71 & .057 & .084 & .15 & .24 \\
\hline GHS 2003 & .97 & .72 & .061 & .084 & .16 & .22 \\
\hline Census 1996 & .89 & .74 & .028 & .053 & .11 & .19 \\
\hline Census 2001 & .94 & .70 & .045 & .070 & .14 & .21 \\
\hline $\begin{array}{l}\text { Notes: Data } \\
\text { sa.gov.za), weig } \\
\text { Survey. Individ } \\
\text { denominators. } \\
\text { explicitly restric } \\
\text { any "don't know } \\
\text { these age groups }\end{array}$ & $\begin{array}{l}\text { calculated from } \\
\text { ited by the pers } \\
\text { als with unkno } \\
\text { he } 1993-1994 \text { } \\
\text { ed to full-time } \\
\text { " or "no respon }\end{array}$ & $\begin{array}{l}\text { the microdata fi } \\
\text { on weights. OH } \\
\text { on and/or imput } \\
1999 \text { OHS did } \\
\text { nly; all other ye } \\
\text { e", suggesting in }\end{array}$ & $\begin{array}{l}\text { es of each sur } \\
=\text { October Ho } \\
\text { d enrollment o } \\
\text { ot collect info } \\
\text { rs include part } \\
\text { putation. Mat }\end{array}$ & $\begin{array}{l}\text { py/census (availa } \\
\text { parental mortal } \\
\text { mation on paren } \\
\text { time students. } \\
\text { rnal and paterna }\end{array}$ & $\begin{array}{l}\text { ble from http:// } \\
\text { uHS = General } \\
\text { y are excluded } \\
\text { al mortality. } \\
\text { ) Microdata do } \\
\text { orphanhood d }\end{array}$ & $\begin{array}{l}\text { www.stats- } \\
\text { Household } \\
\text { from the } \\
\text { ) Enrollment } \\
\text { not include } \\
\text { ata (which in } \\
\text { er years. }\end{array}$ \\
\hline
\end{tabular}

indicating that educational losses from orphaning are minimal. ${ }^{53} \mathrm{Up}$ to this point, the epidemic has had little detrimental effect on physical or human capital accumulation.

The impact of HIV on fertility, a key element in the analysis above, is confirmed in census data. Figure 7.2 graphs the youth population distribution recorded in the past three censuses. In 1991 South Africa had the downward sloping profile typical of an economy with rapid population growth. During the 1990s this profile flattened until, by the time of the 2001 census, the number of teenagers exceeded the number of preteens. These trends are confirmed by data on aggregate school enrollment (figure 7.3) which show a movement from rapid growth to stagna-

${ }^{53}$ Or, alternatively, the reduction in the expected remaining lifespan of, for example, a living 16 year old male from 51.4 years prior to the epidemic to 39.4 years in 2000 has had little effect on the demand for investment in human capital. 
Figure 7.3: Aggregate School Enrollment

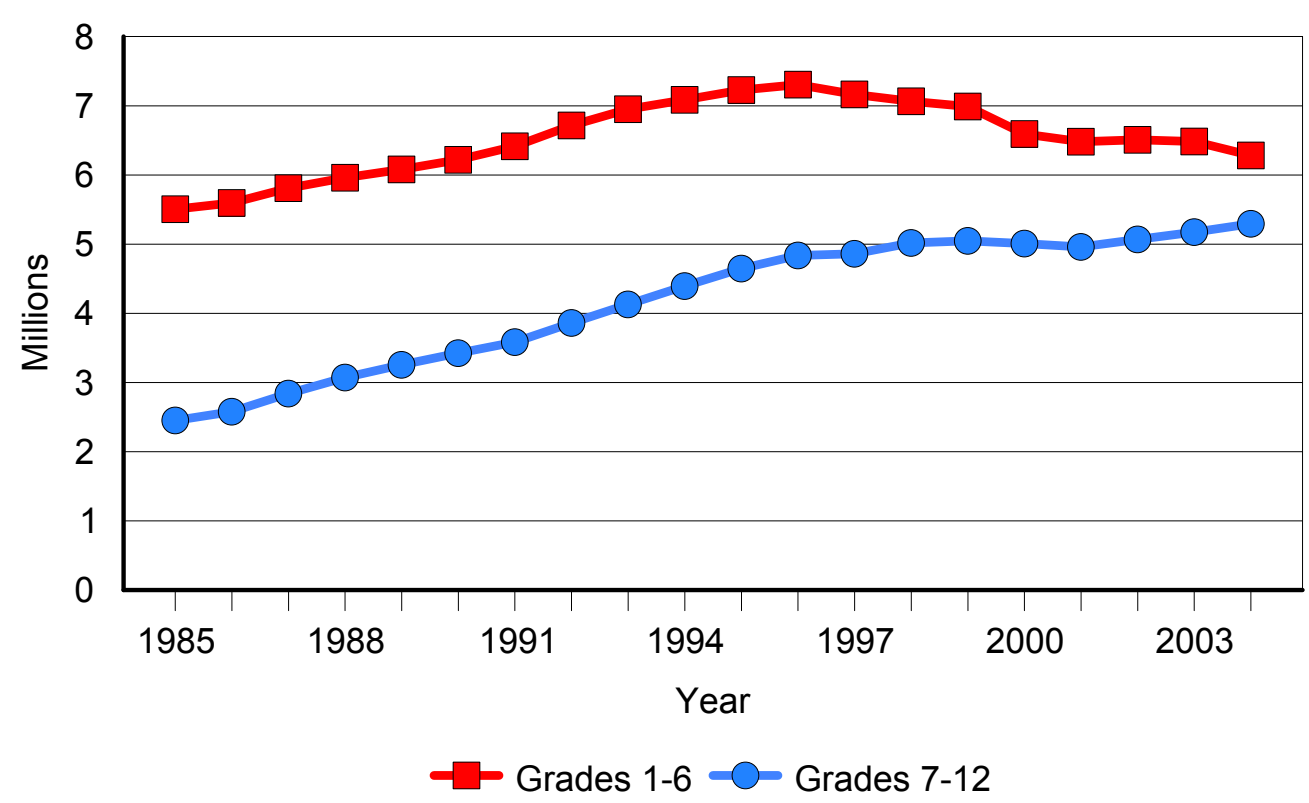

S: Statistics South Africa, RSA Statistics in Brief, and DOE documents.

Figure 7.4: Censuses \& Simulations

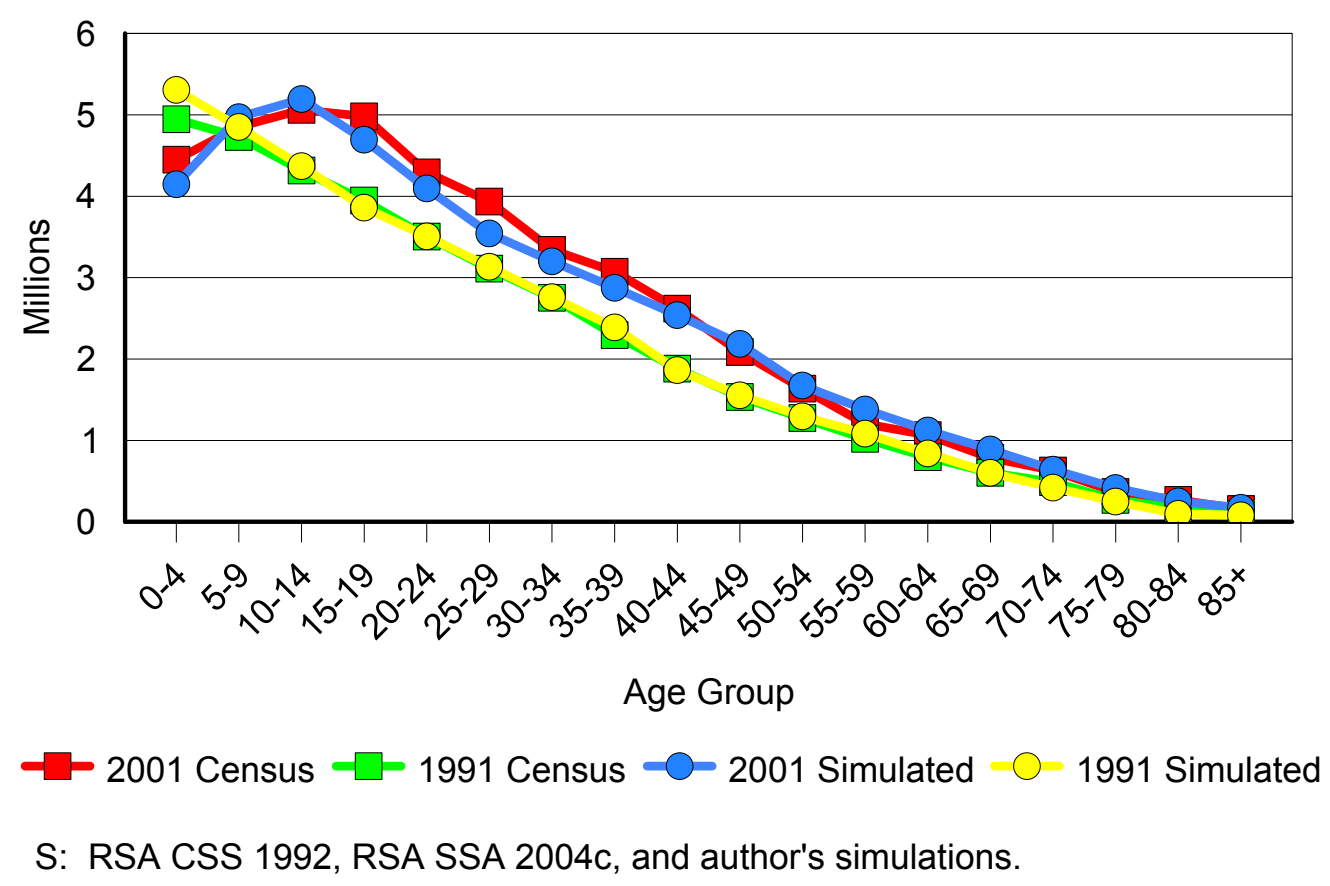


tion and decline. ${ }^{54}$ These data, particularly the ongoing decline in the number of young primary school students, are consistent with a recent, and severe, reduction in fertility. ${ }^{55}$ In Figure $7.4 \mathrm{I}$ graph the 1991 and 2001 population distributions produced by the forward and backward projection of the 1995 OHS in the base HIV simulation earlier above. These simulations, based upon my estimates of the impact of HIV on fertility drawn from a third, independent, source (the DHS), provide a close match to the change in relative cohort sizes present in census data. The inescapable conclusion is that the HIV epidemic has produced an abrupt reduction in fertility, endowing future generations with greater material resources per capita.

Having made a case in favour of the paper, I will now do my best to undermine it, focusing in particular on the fertility trends implied by recent census data. Censuses, especially in third world countries, are bedeviled by the problem of the "undercount." The approach of the Central Statistical Service (now known as Statistics South Africa) in the 1991 census was to completely ignore the census totals ${ }^{56}$ and, instead, project the population distribution from the 1970 census (considered to be accurate) using mortality and fertility estimates, with adjustment and validation

\footnotetext{
${ }^{54}$ Changes in the political boundaries of South Africa, along with the untimely death of the only programmer with access to the education database, have left the South African Department of Education without a time series on enrollment (personal communication with DOE officials). The South African Department of Education graciously provided me with scanned copies of numerous historical documents and reports which I used, along with the historical issues of South African Statistics and Statistics in Brief, to produce the series reported in the table. While there were some minor disagreements among sources, the differences are on the order of $1 \%$ or less. The data refer to ordinary (excluding special education) private and public school students, within the current political boundaries of the Republic of South Africa. The 1985 \& 1986 data do not include White students enrolled in private schools, while the 1997 data do not include private school enrollment (equal to about 250,000 in recent years) for any racial group.

${ }^{55}$ If the reader will compare Figures 7.2 and 7.3, she will see that the growth in the size of census cohorts aged 5-9 and 15-19 between 1991 and 2001 is broadly consistent with the stagnation in primary school enrollment and growth of secondary school enrollment between these two dates, assuming roughly constant enrollment rates.

${ }^{56}$ Apparently, 88 areas were "enumerated" using aerial photography supplemented by spot surveys used to convert houses to individuals, "sweeps" were conducted of entire magisterial districts without enumeration areas, and the census form, to be filled out during the census period by the households themselves, was printed only in English and Afrikaans (RSA CSS 1992, RSA SSA 2004d and 2004e).
} 
against school enrollment data and private sector sample surveys (RSA CSS 1992). The 1996 census adopted a different approach, using a post-enumeration survey to adjust the population totals under the assumption of independence between the original census and post-enumeration samples. Unfortunately, enumeration areas were not properly delineated prior to the Census, ${ }^{57}$ which also only asked for individual first names or initials, with the result that $22 \%$ of the postenumeration sample could neither be classified as a "match" nor a "miss" (RSA SSA 1998). The 2001 census again used a post-enumeration sample, but this time enhanced using bar codes affixed to houses during the original census, more detailed respondent information, and reconciliation visits to ensure matching, all of which reduced unclassified cases to less than $2 \%$ (RSA SSA 2004a). While the 1996 census estimated an undercount of $10.7 \%$, the more carefully executed 2001 census raised the undercount estimate to $17.6 \% .^{58}$ The assumption, used in both censuses, of census and post-enumeration independence is probably flawed, as censuses and surveys in third world countries appear to systematically undercount young persons, ${ }^{59}$ a systematic error which will not be solved by repeated sampling. ${ }^{60}$ Clearly, differences in methodology, and

\footnotetext{
${ }^{57} \mathrm{Bad}$ weather prevented aerial mapping before the census, leading to a reliance on geographic descriptions and household lists given by local authorities.

${ }^{58}$ The 2001 adjustment used an additional reenumeration sample to eliminate overcounts in the original census (e.g. falsifications and duplications), which was not done for the 1996 census. Calculated on the same basis as the 1996 census, the undercount was $20.0 \%$ in 2001 (RSA 2004a).

${ }^{59}$ In my experience this is a consistent problem across a number of countries and samples (to confirm this, one simply has to compare the age distribution of each survey/census with later enumerations, noting the growth in the absolute size of younger cohorts).

${ }^{60}$ As an extreme example, consider the case where enumerators never record persons under age 5. In this case, two random samples of households will still reveal no one under age 5 and the post-enumeration adjusted census population will show no individuals in this age group. The problem here is the assumption of independence, not in the selection of households, but in the coverage of individuals within households. This problem is recognized by Statistics South Africa, which has concluded that both the 1996 and 2001 censuses, after adjustment for the undercount, underestimate the number of 0-4 year olds (RSA SSA 2004b and 2004d). If the reader looks carefully at the data in Figure 7.2, she will see that the absolute size of youth cohorts grows from 1996 to 2001 (simply shift the 1996 curve one position to the right). This is consistent with a systematic failure to enumerate youth, but, of course, could also be produced by the different adjustments for the undercount.
} 
serious concerns about accuracy, make intercensal comparisons of demographic trends highly questionable.

These problems do not negate all of the preceeding discussion. The systematic failure of censuses to enumerate youth does not explain why the relative size of the youngest cohorts is considerably smaller in the 2001 South African census than in the 1996 census, as the two censuses used similar methodologies. Additional data (e.g. on school enrollment and savings) support the assumptions and arguments made in the simulations. Nevertheless, it is the case that aggregate African data, even in one of the most data rich African countries, are highly problematic. For this reason, I have focused on estimates and simulations based upon data from three careful surveys, the OHS, the DHS and the seroprevalence studies of pregnant women. Aggregate data, such as they are, are strongly supportive of the most optimistic of these simulations, indicating a rapid decline in fertility and sustained investment in human and physical capital. 


\section{Conclusion}

Figure 8.1 below graphs my projections of the South African population with and without the HIV epidemic. In the absence of the epidemic, the population would have grown rapidly, reaching 110 million persons by 2050 . With the epidemic, the combination of adult mortality, HIV infant mortality, the powerful effects of community HIV infection on fertility, and the endogenous response of fertility to higher wages contrive to keep the population below 50 million for almost 50 years. As shown in this paper, the positive effects of lower population growth are strong enough to counteract the most pessimistic forecasts of the human capital losses of AIDS orphaned children, implicitly endowing the economy with extra resources which can be used to extend the lifespan of the afflicted and still leave reserves to raise the per capita welfare of future generations.

An emphasis on per capita outcomes is a particularly calloused notion of "welfare", one that does not care about the number of individuals, dead or unborn. It is by no means the way I would evaluate the agonized deaths of millions of young adults and children invaded by infections and cancers. There is, however, a long standing emphasis on GDP per capita in the economics profession as a measure of economic well-being. In the classroom, this has led to the Solovian based lessons on the merits of lower population growth taught to generations of graduate students, while, in the real world, it has supported the encouragement of fertility control through subsidies and, in some cases, draconian coercive measures. One cannot endlessly lament the scourge of high population growth in the developing world and then conclude that a reversal of such processes is an equal economic disaster. The AIDS epidemic is a humanitarian disaster of millenial proportions, one that cries for assistance. It is not, however, an economic disaster. 
Figure 8.1: Population

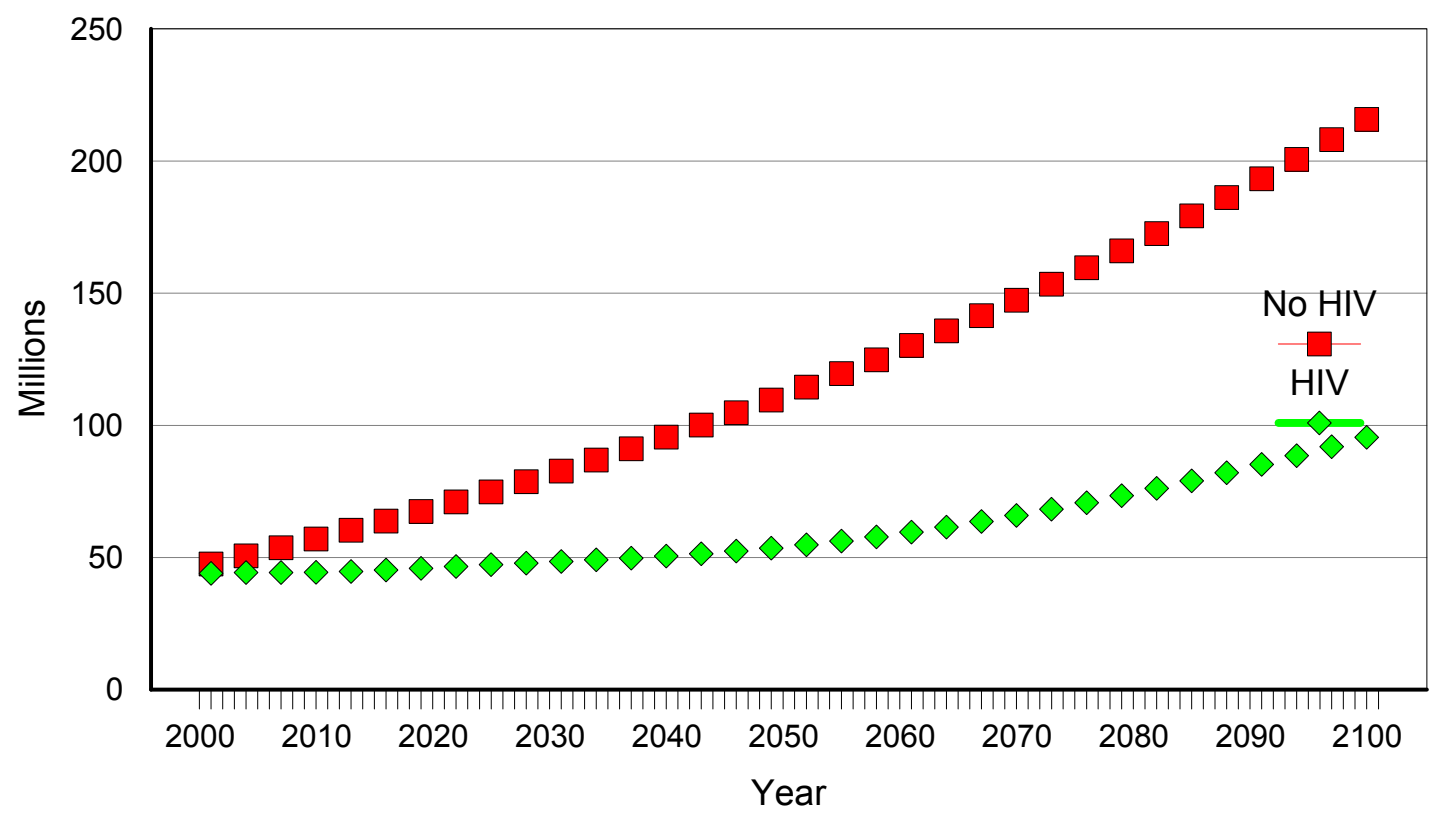




\section{Bibliography}

Arndt, C. and J.D. Lewis. "The Macro Implications of HIV/AIDS in South Africa: A Preliminary Assessment." South African Journal of Economics 68, No. 5 (December 2000): 856-887.

Bell, Clive, Shantanyanan Devarajan and Hans Gerbach. "The Long-run Economic Costs of AIDS: Theory and an Application to South Africa." Working Paper, June 2003.

Bobat, Raziya, Hoosen Coovadia, Dhayendre Moodley, et al. "Mortality in a cohort of children from to HIV-1 infected women from Durban, South Africa." South African Medical Journal 89, No. 6 (1999): 646-648.

Bloom, David S. and Ajay S. Mahal. "Does the AIDS epidemic threaten economic growth?" NBER Working Paper No. 5148. Cambridge, MA: National Bureau of Economic Research, 1995.

Bureau of Labor Statistics. 2000 Consumer Expenditure Interview Survey Public Use Microdata Documentation. February 15, 2002.

Carpenter, Lucy M., Anatoli Kamali, Anthony Roberantwari, et al. "Rates of HIV-1 transmission within marriage in rural Uganda in relation to the HIV sero-status of the partners." AIDS 13 (1999): 1083-1089.

Carpenter, Lucy M., Jessica S. Nakiyingi, Anthony Ruberantwari, et al. "Estimates of the impact of HIV infection on fertility in a rural Ugandan population cohort." Health Transition Review 7, Supplement 2 (1997): 113-126.

Case, Anne, Christina Paxson and Joseph Ableidinger. "Orphans in Africa: Parental Death, Poverty and School Enrollment." Manuscript. Princeton University, March 2004.

Centers for Disease Control and Prevention. "Births: Final Data for 2000." National Vital Statistics Report 50, No. 5 (February 12, 2002).

Council of Economic Advisers. Economic Report of the President - February 2003. Washington, D.C.: United States Government Printing Office, 2003.

Davidson, Russell and James G. MacKinnon. Estimation and Inference in Econometrics. New York: Oxford University Press, 1993.

Deaton, Angus and John Muellbauer. Economics and Consumer Behavior. Cambridge: Cambridge University Press, 1980.

Epstein, Larry G. "Generalized Duality and Integrability." Econometrica 49, No. 3 (May 1981): 655-678.

Evans, David and Edward Miguel. "Orphans and Schooling in Africa: A Longitudinal Analysis." Manuscript. Harvard and UC Berkeley, February 2004.

Goering, Laurie. "Official AIDS remedy: Garlic, etc." Chicago Tribune. 15 March 2004. Section 1, p. 4. 
Goldberg, P.J.P. Women, Work, and Life Cycle in a Medieval Economy: Women in York and Yorkshire. New York: Oxford University Press, 1992.

Gourieroux, C., A. Monfort and A. Trognon. "Pseudo Maximum Likelihood Methods: Theory." Econometrica 52, No. 3 (May 1984): 681-700.

Gray, Ronald H., Maria J. Wawer, David Serwadda, et al. "Population-based study of fertility of women with HIV-1 infection in Uganda." Lancet 351 (1998): 98-103.

Hatcher, John. Plague, Population and the English Economy 1348-1530. London: Macmillan Press, 1977.

Hausman, Jerry, Bronwyn H. Hall and Zvi Griliches. "Econometric Models for Count Data with an Application to the Patents R\&D Relationship." Econometrica 52, No. 4 (July 1984): 909-938.

Heston, Alan, Robert Summers and Bettina Aten. Penn World Table Version 6.1. Center for International Comparisons at the University of Pennsylvania (CICUP), October 2002. http://pwt.econ.upenn.edu.

Hira, S.K., B.M. Nkowane, J. Kamanga, et al. "Epidemiology of Human Immunodeficiency Virus in Families in Lusaka, Zambia." Journal of Acquired Immune Deficiency Syndromes 3 (1990): 83-86.

Human Sciences Research Council. Nelson Mandela/HSRC Study of HIV/AIDS Household Survey 2002. Cape Town, South Africa: Human Sciences Research Council Publishers, 2002.

Hunter, Susan-Catherine, Raphael Isingo, J. Ties Boerma, et al. "The Association Between HIV and Fertility in a Cohort Study in Rural Tanzania." Journal of Biosocial Science 35 (2003): 189-199.

Killingsworth, Mark R. and Heckman, James J. "Female Labor Supply: A Survey." In Handbook of Labor Economics, Vol. I, ed. Orley Ashenfelter and Richard Layard, 103-204. Amsterdam: North-Holland, 1986.

Lloyd, Cynthia B. and Ann K. Blanc. "Children's Schooling in sub-Saharan Africa: The Role of Fathers, Mothers and Others." Population and Development Review 22, No. 2 (June 1996): 265-298.

Marins, Jose Ricardo P., Leda F. Jamal, Sanny Y. Chen, et al. "Dramatic improvement in survival among adult Brazilian AIDS patients." AIDS 17 (2003): 1675-1682.

McNeil, Donald G. Jr. "Plan to Battle AIDS Worldwide Is Falling Short." New York Times. 28 March 2004.

Morgan, Dilys, S.S. Malamba, B. Mayanja, et al. "Survival by AIDS defining condition in rural Uganda." Sexually Transmitted Infections 76, No. 3 (June 2000): 193-197.

Murphy, Kevin M. and Robert H. Topel. "Estimation and Inference in Two-Step Econometric Models." Journal of Business and Economic Statistics 3, No. 4 (1985): 370-379. 
Over, Mead. "The Macroeconomic Impact of AIDS in Sub-Saharan Africa." Working Paper. Population and Human Resources Department, World Bank, June 1992.

Phelps-Brown, E.H. and Sheila V. Hopkins. "Seven Centuries of the Prices of Consumables, Compared with Builders' Wage-Rates." Economica 23, No. 92 (1956): 296-314.

Poos, L.R. A rural society after the Black Death: Essex 1350-1525. Cambridge: Cambridge University Press, 1991.

Republic of South Africa. Central Statistical Service. Population Census 1991: Adjustment for Undercount. CSS Report No. 03-01-26 (1991). Pretoria, South Africa: Central Statistical Service, 1992.

Republic of South Africa. Central Statistical Service. RSA Statistics in Brief. Pretoria, South Africa: Central Statistical Service, annual issues.

Republic of South Africa. Central Statistical Service. Statistics South Africa. Pretoria, South Africa: Central Statistical Service, annual issues.

Republic of South Africa. Department of Health. "National HIV and Syphilis Sero-Prevalence Survey of women attending Public Antenatal Clinics in South Africa 2000." South Africa: Department of Health, 2001.

Republic of South Africa. Department of Health. "Summary Report: National HIV and Syphilis Sero-Prevalence Survey in South Africa 2001." South Africa: Department of Health, 2002.

Republic of South Africa. Department of Health, Eastern Cape. Eastern Cape Epidemiological Notes, October 2000. Vol. 12, Year 3, Issue 4. Bisho, South Africa: Department of Health, 2000.

Republic of South Africa. Department of Health, Free State. "HIV Antenatal Survey Report 1999." South Africa: n.p., n.d.

Republic of South Africa. Statistics South Africa. Recorded Deaths 1995. Statistical release PO309. Pretoria, South Africa: Statistics South Africa, 1997.

Republic of South Africa. Statistics South Africa. The people of South Africa. Population census, 1996: Calculating the undercount in census '96. Report no. 03-01-18 (1996). Pretoria, South Africa: Statistics South Africa, 1998.

Republic of South Africa. Statistics South Africa. South African Life Tables: 1985-1994 and 1996. Report No. 02-06-04. Pretoria, South Africa: Statistics South Africa, 2000.

Republic of South Africa. Statistics South Africa. Advance release of recorded deaths 1997-2000. Statistical release PO309.1. Pretoria, South Africa: Statistics South Africa, $2001 \mathrm{a}$.

Republic of South Africa. Statistics South Africa. Recorded live births 1998-2000. Pretoria: Statistics South Africa, 2001b. 
Republic of South Africa. Statistics South Africa. Census 2001. Post-enumeration survey: Results and methodology. Report no. 03-02-17 (2001). Pretoria, South Africa: Statistics South Africa, 2004a.

Republic of South Africa. Statistics South Africa. "Extract from the Report of the Census SubCommittee to the South African Statistics Council on Census 2001." http:// www.statssa.gov/census01/html/Stats\%20Council\%20Health\%20Warnings.asp (as of September 30, 2004b).

Republic of South Africa. Statistics South Africa. Primary tables South Africa: Census '96 and 2001 compared. Report No. 03-02-04 (2001). Pretoria, South Africa: Statistics South Africa, 2004c.

Republic of South Africa. Statistics South Africa. "The Count and How it Was Done. Chapter 7: Issues and unexpected findings in Census '96, and possible explanations for them." htt p://www.statssa.gov/za/census01/Census96/HTML/Metadata/Docs/count/chapter_7.htm (as of September 30, 2004d).

Republic of South Africa. Statistics South Africa. "Why Census '96 results are the best ever." http://www.statssa.gov/za/census01/Census96/HTML/press/Part003.html (as of September 30,2004 e).

Saltmarsh, John. "Plague and Economic Decline in England in the Later Middle Ages." Cambridge Historical Journal 7 (1941): 23-41.

Serwadda, David, Ronald H. Gray, Maria J. Wawer, et al. "The social dynamics of HIV transmission as reflected through discordant couples in rural Uganda." $\underline{\text { AIDS }} 9$ (1995): 745-750.

Steffen, Gustaf F. Studien zur Geschichte der Englischen Lohnarbeiter. Stuttgart, Germany: Hobbing \& Büchle, 1901.

Strauss, J.P. Results of the Monitoring Learning Achievement Project. Bloemfontein, South Africa: Research Institute for Education and Planning, 1999.

UNAIDS Reference Group on Estimates, Modelling and Projections. "Improved methods and assumptions for estimation of the HIV/AIDS epidemic and its impact." AIDS 16 (2002): W1-W14.

Unicef. "Mother-to-Child Transmission of HIV." New York: United Nations Children's Fund, 2002.

Winkelmann, Rainer and Klaus F. Zimmerman. "A new approach for modeling economic count data." Economics Letters 37 (1991): 139-143. 


\section{Appendix: Construction of Variables from the Microdata Sets}

The variables used in Section IV and Table I are constructed as follows:

Wages per Hour - Individuals in the OHS report whether they work for someone else or for themselves. Those working for someone else report their income from their main job, precisely or in terms of a range (e.g. R2000-R2499), and whether this income is daily, weekly, monthly or annual. I multiply the daily, weekly and monthly incomes (or income brackets) by 240,48 and 12 , respectively, to arrive at annual incomes. Individuals also report their weekly income in kind received in the form of transport, food and other. I multiply these by 48 and add them to wage income, treating entries with no reports as values of zero. I take annual taxes as the reported amount deducted per day, week, month or year (imputing a value of zero for blank entries), multiplied by the factors listed above. ${ }^{61}$ Dividing by the response to the question on hours of work in the last 7 days the individual worked, yields my estimate of annual before and after tax wage income per weekly hour of work. I exclude from the sample a few hundred individuals who report that they work both for themselves and for others. The behavioral equations (3)-(6) of Table I exclude individuals under the age of 25, as their education, determining their lifetime behavior, is as yet incomplete. However, I include all individuals, including those under 25, in the wage regressions of columns (1)-(2), under the assumption that their incomes appropriately reflect the return to their current educational capital. Excluding individuals under 25 or, as noted in the paper, multistep procedures to adjust for selectivity bias, both have little effect on the estimated educational profile of wages.

Hours of work - The dependent variable in columns (3) and (4) of Table I is the number of hours of work during the last 7 days that the individual worked (values of zero are entered for individuals who were not working). The sample covers all individuals over the age of 25 for which I have data on educational attainment.

Education - Individuals surveyed in the OHS and DHS report their highest standard passed or education level obtained, with some grouping of levels and some differences in choices between the surveys. I convert these into standardized years of education for the regressions of columns (1) and (2) of Table I as follows: (i) No schooling or less than one year completed $=0$ years; (ii) Sub A/sub B/grade 1/grade 2/Std $1=2$ years; (iii) Standards 2 - $10=$ standard year + 2; (iv) Diploma/certificate with Std 9 or lower or further studies incomplete $=13$ years; (v) Diploma/certificate with Std 10 or diploma/other postschool complete $=14$ years; (vi) Degree or further degree complete $=16$ years. These 14 educational categories are then used to identify the impact of wage income in columns (3)-(6) of Table I and constitute the educational state space of column (6)'s ordered probit and the simulations in the paper.

Fertility - I use women's reports of their past pregnancies in the DHS to reconstruct the number of births in each year of their lives. I count pregnancies that were lost before term or resulted in stillbirths as births, under the assumption that the infant mortality estimates I derive from the OHS include such deaths. As shown in the unpublished appendix, the resulting estimates of fertility and mortality reproduce the OHS adult population distribution. If the definition of a pregnancy is restricted to a live birth, and the OHS infant mortality rates are then applied, predicted historical cohort sizes are too small. Although I exclude from the sample women younger than 25 at the time of the survey, fertility at earlier ages is captured by the retrospective

${ }^{61}$ As noted in Section IV above, I get fairly similar model results when I use the tax code to calculate after tax incomes. 
histories of older women. I restrict the sample to completed years of life, i.e. do not include the fertility history since each woman's last birthday which, for obvious calendar reasons, shows systematically lower fertility rates.

Mother's Education - Individuals in the OHS report their relationship to the head of the household and the respondent numbers of their parents, if these are members of the household. I use this information to construct two sets of identified mothers: (1) Based upon relationship, where mothers are either the head of the household where the respondent (the child) reports being the son or daughter of the household head, or mothers are respondents who report that they are the parent of the head of the household (the child). I eliminate cases where the age difference between the presumed mother and child is less than 12 or more than 60 years or where multiple women claim to be the mother of the household head. (2) Based upon the reported respondent number of mothers, eliminating cases where the reported "mother" is male, where the age difference between mother and child is less than 12 or more than 60 years, or where the mother and child's individually reported relationships to the household head are incompatible (e.g. when the mother claims to be the daughter of the household head, but the child does not claim to be the grandchild of the household head). I then merge the two sets of information, giving precedence to mothers identified on the basis of reported relationship in the 81 cases where the datasets disagree.

Non-AIDS Mortality - Although not shown in Table I, I use the OHS sample reports of deaths in the household in 1994-1995 to estimate mortality in the absence of AIDS. I add individuals who reportedly died in the period November 1994-October 1995 to the sample of surviving individuals and run probits for the probability of death in a given year on sex and a quadratic in age. I divide the sample into two groups, aged 0-11 and 12-99, so as to allow simple quadratics in age to capture the rapid decline of youth mortality and rise of adult mortality with age. As the sex dummy is not a significant determinant of youth mortality, I exclude sex from the final estimating equation for that group. As shown in the unpublished appendix, my estimates of pre-AIDS mortality match the historical evolution of the South African population. In the simulations, I assume that mortality due to AIDS and non-AIDS causes are independently distributed.

CES data - To predict the behavior of the US population using the SA coefficient estimates, I make use of the interview survey data files of the 2000 consumer expenditure survey, which includes five quarterly interviews running from first quarter of 2000 through the first quarter of 2001. I measure after tax incomes as the family member's gross pay minus federal and state taxes deducted (grospayx-amtfed-sltaxx), multiplying by 48, 24, 12, 4 and 24 to convert weekly, biweekly, monthly, quarterly and bimonthly reports to annual values ("other", i.e. unknown, payperiods are dropped from the sample). Hours of work are measured as the family member's usual weekly hours of work (inc_hrsq). I then use an interval regression (to account for topcoding) to estimate a wage regression as in column (2) of Table I, restricting the sample to employees (incomey $\leq 4$ ). Education is naturally coded in years, except for post secondary, where I count some college or associate degrees as 14 years, bachelor's as 16 years and master's and above as 18 years. After estimating the wage equation, I use it to predict the behavior of the 2000 US population using the 5 quarters of the CES population sample with weights adjusted for months in the scope of the 2000 year (finlwt $21^{*}$ mo_scope/12). I identify mothers in cases where members identify themselves as the child of the household reference person by using the reference person (if female) or the spouse of the reference person (if the reference person is male). I also identify mothers using female individuals who report themselves as the mother of the reference person (the child). In all cases, I drop observations where the age difference between mother and child is less than 12 or more than 49 years. 